Florida International University FIU Digital Commons

\title{
An Investigation of the Relationship Between Maltreatment and Alcohol and Other Drug (AOD) Use Among African-American and Hispanic Adolescent Girls
}

Calonie Marie Kelli Gray

Florida International University, calonie.gray1@fiu.edu

DOI: $10.25148 /$ etd.FI10022517

Follow this and additional works at: https://digitalcommons.fiu.edu/etd

\section{Recommended Citation}

Gray, Calonie Marie Kelli, "An Investigation of the Relationship Between Maltreatment and Alcohol and Other Drug (AOD) Use Among African-American and Hispanic Adolescent Girls" (2009). FIU Electronic Theses and Dissertations. 204.

https://digitalcommons.fiu.edu/etd/204 


\section{FLORIDA INTERNATIONAL UNIVERSITY \\ Miami, Florida}

AN INVESTIGATION OF THE RELATIONSHIP BETWEEN MALTREATMENT AND ALCOHOL AND OTHER DRUG (AOD) PROBLEMS IN AFRICANAMERICAN AND HISPANIC ADOLESCENT GIRLS

A dissertation submitted in partial fulfillment of the requirements for the degree of DOCTOR OF PHILOSOPHY in PSYCHOLOGY

by

Calonie Marie Kelli Gray 
To: Dean Kenneth Furton

College of Arts and Sciences

This dissertation, written by Calonie Marie Kelli Gray, and entitled An Investigation of the Relationship Between Maltreatment and Alcohol and Other Drug (AOD) Problems in African-American and Hispanic Adolescent Girls, having been approved in respect to style and intellectual content, is referred to you for judgment.

We have read this dissertation and recommend that it be approved.

James Jaccard

William Kurtines

Eric Wagner

Marilyn J. Montgomery, Major Professor

Date of Defense: March 24, 2009

The dissertation of Calonie Marie Kelli Gray is approved.

$\begin{array}{r}\begin{array}{r}\text { Dean Kenneth Furton } \\ \text { College of Arts and Sciences }\end{array} \\ \hline \begin{array}{r}\text { Dean George Walker } \\ \text { University Graduate School }\end{array}\end{array}$

Florida International University, 2009 


\section{DEDICATION}

This dissertation is dedicated to my father who left with me a legacy of hope, determination, and positivity. 


\section{ACKNOWLEDGMENTS}

It is with a heart of sincere gratitude and appreciation that I acknowledge Marilyn Montgomery, my mentor and guide throughout this process. Her keen eye for detail and gifted ability to synthesize have been invaluable to my success. I would also like to thank Eric Wagner, who always offered professional and personal support for each project I have undertaken. His commitment to my success is something that I will always cherish.

I would also like to extend much thanks to William Kurtines and James Jaccard who both offered feedback, time, and generous amounts of support.

I would especially like to thank each and every member of the McKnight Family. The McKnight Family has been an instrument of financial, emotional, and professional support. I would like to make special mention of Charles Jackson, Dr. Morehouse, Guitele Rahill, and Anthony Burrow who each touched my life in very different, yet very special ways.

I would like to thank my FIU support group, Sandra Williams, Sabrina Des Rosiers and Rona Carter for their countless and priceless help every step of the way. Last but certainly not least, I would like my family, Barbara Gray, Jackea Gray, Candi Burton and my boyfriend, Christopher Hickman for their willingness to stick by me and support

me in making the sacrifices that have led me to this point. I could not have completed one day in the program without your love and encouragement. 


\title{
ABSTRACT OF THE DISSERTATION \\ AN INVESTIGATION OF THE RELATIONSHIP BETWEEN MALTREATMENT AND ALCOHOL AND OTHER DRUG (AOD) PROBLEMS IN AFRICAN- AMERICAN AND HISPANIC ADOLESCENT GIRLS
}

by

\author{
Calonie Marie Kelli Gray \\ Florida International University, 2009 \\ Miami, Florida \\ Marilyn Montgomery, Major Professor
}

Maltreatment experienced in childhood or adolescence is a known risk factor for later problem alcohol and/or other drug (AOD) use (Bailey \& McCloskey, 2005; Shin, Edwards, Heeren, 2009). A growing body of empirical work has found significant associations between adolescent girls' AOD use and maltreatment experiences. However, questions remain as to how this relation unfolds with African-American and Hispanic adolescent girls. Guided by four relational models that have been proposed in the literature, this study examined the links between maltreatment, trauma symptoms, and alcohol and/or other drug (AOD) problems in a sample of 170 African-American and Hispanic adolescent girls who were participants in a school-based AOD use intervention.

Results of this study revealed that maltreatment experiences (physical and emotional abuse) were positively related to trauma symptoms, which were positively related to AOD problem severity, alcohol abuse, alcohol dependency, drug abuse, and drug dependency. Perceived discrimination moderated this relation between sexual abuse and trauma symptoms, such that more perceived discrimination resulted in a stronger 
effect of sexual abuse on trauma symptoms. Ethnic identity moderated the relation between sexual abuse and AOD problem severity, such that ethnic identity demonstrated protective properties in the relation between sexual abuse and AOD problem severity. My research adds to extant knowledge on the relation between maltreatment and AOD use in adolescent girls and suggests the importance of developing interventions targeting maltreatment and AOD use concurrently. 


\section{TABLE OF CONTENTS}

CHAPTER

PAGE



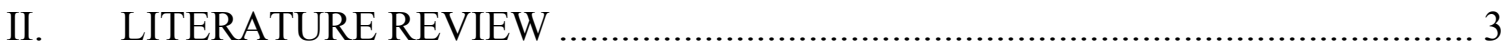

Adolescent Girls and AOD Problems................................................................... 4

Maltreatment and Adolescent Girls ..................................................................... 4

Effects of Maltreatment Experiences ............................................................................ 6

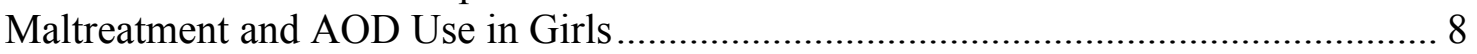





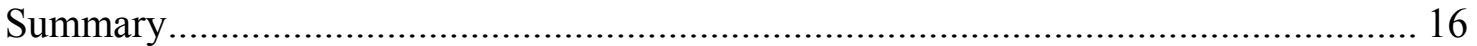



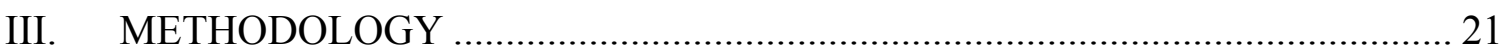

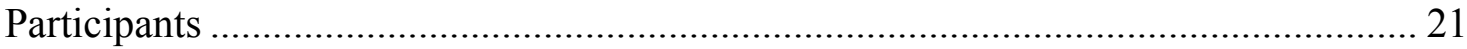

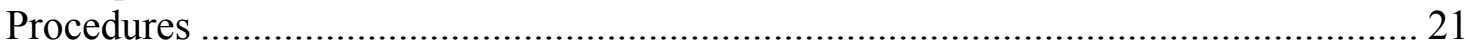



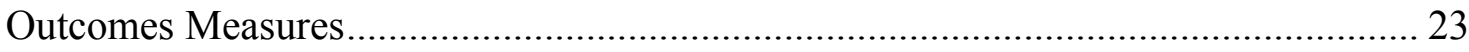

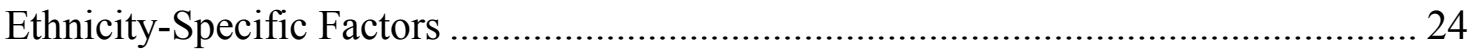







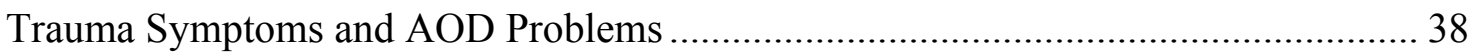

Impact of Ethnicity-Specific Factors ..................................................................... 40

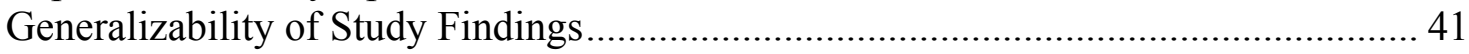

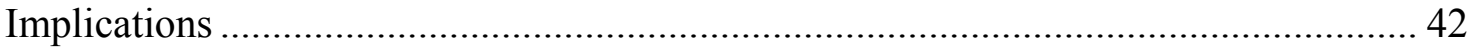

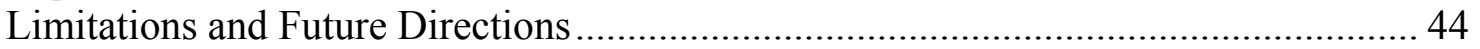

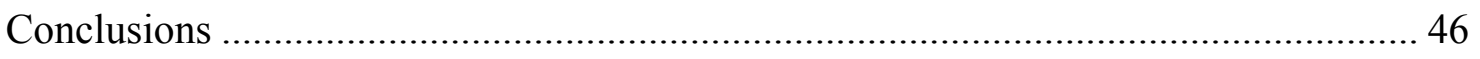

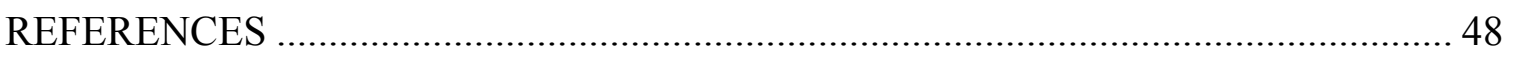

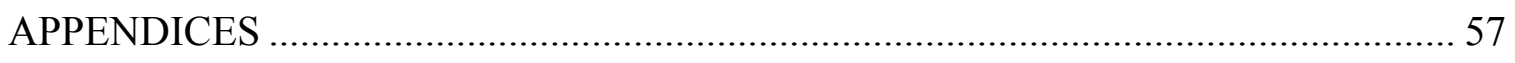

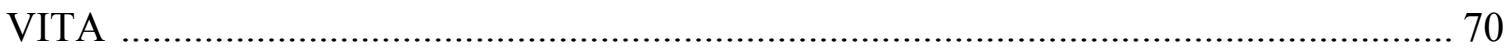




\section{LIST OF TABLES}

TABLE

PAGE

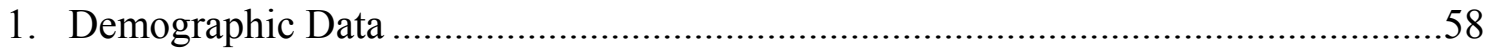

2. Descriptive Statistics for Study Variables ......................................................59

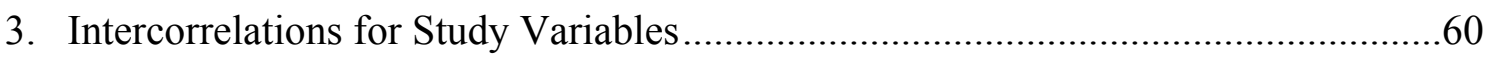

4. Mean Differences for AOD Problem Severity....................................................61

5. Significant Model Pathway Coefficients ............................................................62

6. Mean Differences for African-Americans and Hispanics....................................63 


\section{LIST OF FIGURES}

FIGURE

PAGE

1. Four Proposed Conceptual Models ...................................................................65



3. Final Structural Model ..................................................................................6

4. Moderated Relation of Sexual Abuse and Trauma Symptoms by Perceived Discrimination. .68

5. Moderated Relation of Sexual Abuse and AOD Problem Severity by Ethnic Identity 


\section{CHAPTER I}

\section{INTRODUCTION}

Maltreatment experienced in childhood or adolescence is a known risk factor for later alcohol and/or other drug (AOD) problems (Bailey \& McCloskey, 2005; Shin, Edwards, Heeren, 2009). Currently, the prevalence of AOD use and maltreatment among adolescents are issues of growing public health concern for many researchers and treatment professionals. A small, but emerging literature has documented significant associations between adolescent girls' AOD use and maltreatment experiences. The pervasiveness of girls' maltreatment experiences has been established for decades, and adolescent girls' underage drinking and drug use has also become more common in the past decade. However, few researchers have undertaken empirical studies evaluating the associations between maltreatment experiences and AOD use specifically with adolescent girls. Despite the prevalence of these factors that have a negative impact on girls' developmental outcomes, few explanatory models linking maltreatment and girls' adolescent risk behaviors have been presented in the literature.

Precise explanations of the association between adolescent AOD use and maltreatment experiences with girls are needed so that interventions can be targeted to alleviate the societal burden. Without proper intervention, AOD use and maltreatment experiences in adolescence are often predictors for subsequent maladaptive outcomes in

adulthood. Some of these outcomes include parental dysfunction (including child abuse), adult AOD abuse and dependency (Locke \& Newcomb, 2003), dysfunctional interpersonal relationships, and chronic mental health concerns (Gutierres \& Todd, 
1997). Thus, the sequelae of girls' AOD use and maltreatment experiences result in substantial economic and societal costs.

In addition to the paucity of gender-specific literature on adolescent AOD use and maltreatment in family relationships, there is virtual absence of literature addressing raceor ethnicity-specific links between maltreatment and adolescent AOD use. AfricanAmerican and Hispanic adolescent girls have been understudied, in particular. Recent empirical research has shown some ethnicity-specific risk factors related to adolescent AOD use, including victimization experiences, acculturation and acculturation stressors, perceived discrimination, familial dynamics, religious affiliation, etc. (as cited in Amaro, Blake, Schwartz, \& Flinchbaugh, 2001). Given these findings it is probable that some differential developmental outcomes exist with regard to the association of AOD problems and maltreatment among African-American and Hispanic adolescent girls. Research findings displaying these links would be crucial for the development of specialized interventions African-American and Hispanic adolescent girls. To date, no studies have evaluated an intervention for African-American and Hispanic adolescent girls that directly targets both AOD problems and the effects of maltreatment.

A broader understanding of the association of maltreatment experiences and AOD problems in African-American and Hispanic adolescent girls is fundamental in positing more precise explanations on the developmental impact of maltreatment on adolescent girls. Thus, the proposed study seeks to address the gaps in knowledge regarding these potential links that exist via both empirical and theoretical investigation. In the next chapter, an in-depth review of the literature comprising previous research on maltreatment and AOD use in adolescent girls will be presented. 


\section{CHAPTER II}

\section{LITERATURE REVIEW}

According to the most recent findings from the Monitoring the Future study (Johnston, O’Malley, Bachman, \& Schulenberg, 2008), adolescent girls in the $8^{\text {th }}$ grade have consistently had higher 30-day prevalence of alcohol use than boys since 2002. Moreover, in a series of subgroup analyses of trends in adolescent AOD use using historical MTF data, Johnston and his colleagues (2007) found that $8^{\text {th }}$ grade adolescent girls have had higher illicit drug use rates (excluding marijuana) than boys for the last decade. These statistics reveal the necessity for better explanations regarding potential factors impacting adolescent girls' patterns of substance use.

African-American adolescents have lower AOD use rates than White NonHispanic and Hispanic adolescents. Moreover, Hispanic adolescents have higher AOD use levels than African-American adolescents and lower AOD use levels when compared to White Non-Hispanic adolescents (Johnston et al., 2008). The MTF data also showed that in 8th grade, Hispanics have higher drug use (except amphetamines) than both White Non-Hispanics and African-Americans. Notwithstanding the salient ethnic group difference in AOD use patterns among adolescents in general, the ethnic group differences in adolescent girls' AOD use have not been explored. These points highlight the importance of investigating the nuanced relations of adolescent girls' AOD use patterns in ethnic minority populations. The knowledge acquired through such efforts has implications for the development of more efficacious treatment for diverse adolescent girls. 


\section{Adolescent Girls and AOD Problems}

Among adolescent girls and boys that engage in AOD use, the developmental pathways to AOD problems tend to differ. Adolescent girls progress more rapidly from regular alcohol use to alcohol abuse and are more likely to become addicted to cocaine than adolescent boys (CASA, 2003). Additionally, research has found that girls have more AOD-use related hospital and physician visits than their male counterparts (Newcomb \& Bentler, 1987; Johnson \& Richter, 2002) because of the increased negative health effects AOD use has on girls vs. boys (Ely, Hardy, Longford, \& Wadsworth, 1999). Adolescent girls who use AOD are more likely to report feelings of depression and loneliness and thoughts of suicide than girls who do not use AOD (CASA, 2003).

In one longitudinal study, 488 adolescent girls in New Zealand were followed from ages 13 to 18 years old (Fergusson \& Woodward, 2000). The findings in this study revealed significant associations between AOD use and delinquent peer association, conduct problems, poor academic performance, risky sexual behaviors, and commission of crimes with adolescent girls. Similar findings have been revealed in national studies (e.g., Kilpatrick, Aceirno, Saunders, Resnick, Best, \& Schnurr, 2000; Bryant, Schulenberg, O’Malley, Bachman, \& Johnston, 2003). Moreover, substantial research has shown how these behaviors lead to chronic AOD problems, including AOD abuse and dependency with girls (Armstrong \& Costello, 2002).

\section{Maltreatment and Adolescent Girls}

As with adolescent AOD use, adolescent maltreatment is also of great public health concern. Any form of neglect, physical abuse, emotional abuse, sexual abuse, or any combination of these that occurs constitutes maltreatment. According to the reports 
of many national studies investigating the prevalence of maltreatment, the percentages of adolescent maltreatment cases range from $25-45 \%$ of total reported maltreatment cases (Smith, Ireland, \& Thornberry, 2005). The US Department of Health and Human Services (DHHS) reported that for adolescents ages 12-15 the incidence rate for maltreatment in 2003 was 10.7 per 1000 adolescents. For adolescents ages $16-17$ the incidence rate was 5.9 per 1000 adolescents (DHHS, 2005). Recent numbers are equally as staggering with estimations of 10.2 per 1000 adolescents ages $12-15,6.3$ per 1000 adolescents ages 16-17, and 19.8 per 1000 African-American children and adolescents maltreated in 2006 (DHHS, 2008). These statistics reveal why the scrutiny of maltreatment experiences in adolescents is imperative.

Maltreatment in adolescent girls has been inadequately studied in ethnic minority populations, namely Hispanic and African-American populations. However, there may well be ethnic variations in the sequelae of adolescent maltreatment episodes (e.g., substance use patterns, trauma symptoms, adjustment issues, etc.). Given the scant literature on African-American and Hispanic adolescent girls' maltreatment experiences, there are few ethnicity-specific factors mentioned in the following sections. None of the studies highlighted in the following sections included sizeable numbers of ethnic minorities in their samples. Nevertheless, to understand the association of maltreatment experiences and AOD use in understudied populations like minority adolescent girls, a good first step is to review previous research findings for maltreatment among adolescents, in general, as factors relevant across population groups may be present, although not yet specifically studied in particular minority groups. 


\section{Effects of Maltreatment Experiences}

The impact of maltreatment on adolescents is multi-fold. The results of maltreatment episodes have been shown in the literature to vary on a spectrum from mild adjustment issues to suicide (e.g., Kilpatrick et al., 2000; Thompson, Kaslow, Lane, \& Kingree, 2000). In one landmark study, a national sample of 2006 adolescents (48\% girls, $10 \%$ African-American, $7 \%$ Hispanic) was assessed for maltreatment experiences (Boney-McCoy \& Finkelhor, 1995). Adolescents and their parents were both interviewed to assess for types of maltreatment experienced by adolescents (i.e., aggravated assault, simple or physical assault by non-family member, simple or physical assault by parents, simple or physical assault by family members other than parents, attempted kidnapping, and sexual assault). Additionally, adolescents were assessed for trauma symptoms, general sadness, and trouble with their teachers. Ethnicity was included in the analyses as a covariate (i.e., dummy-coded "Black or not" and "White or not").

Boney-McCoy and Finkelhor (1995) found that 33\% of girls and 47\% of boys had experienced at least one form of maltreatment. According to the statistical results, sexual assault when compared with other forms of maltreatment appeared to have the most deleterious effects on adolescent girls. These researchers noted that even minimallyinvasive forms of sexual maltreatment (i.e., sexual advances without physical contact) were associated with high levels of symptomology. Sexually assaulted girls had high levels of trauma symptoms and were 120 times more likely to have problems with teachers than non-sexually assaulted girls. No ethnicity-specific effects were noted. Given the study's cross-sectional design, the primary findings left unanswered questions 
as to whether trauma symptoms are risk factors or sequelae of maltreatment experiences in adolescents.

Boney-McCoy and Finkelhor (1996) decided to explore the findings from their first study into greater depth by investigating maltreatment and symptomology from a longitudinal perspective. These researchers wanted to identify a maltreatmentsymptomology casual link, which had not and could not have been done in previous cross-sectional research studies. They analyzed a subset of the data from their original study, including 8\% African-American and 6\% Hispanic adolescents. These researchers assessed for prior maltreatment experiences and current levels of trauma and depression symptoms (Time 1). About 15 months later, adolescents were queried for any "interim" maltreatment incidents (Time 2). The adolescents' trauma and depression symptoms were assessed again at Time 2 . The data were collected at 2 time-points in an effort to control for effects of prior maltreatment in the analyses (i.e., have baseline data). The results of this study showed that maltreatment experiences were followed by trauma and depression symptoms. Their longitudinal findings were consistent with cross-sectional research which suggested that maltreatment preceded symptomology. Additionally, Boney-McCoy and Finkelhor found that maltreatment experiences coupled with poorquality parental relationships exacerbated trauma symptoms and depression levels. As in their first study, these researchers did not assess ethnicity-specific effects.

Both Boney-McCoy and Finkelhor studies were conducted a little over a decade ago. These two studies considered the mental health effects of maltreatment on adolescents. Experiences of maltreatment have been consistently reported in the literature to have myriad impacts on psychological functioning (e.g., Bailey \& 
McCloskey, 2005; Lipschitz, Rasmusson, Anyan, Cromwell, \& Southwick, 2000; Titus, Dennis, White, Scott, \& Funk, 2003). Until recently, much of the extant research regarding maltreatment and trauma symptoms had been situated in the adult literature, comprising retrospective self-reports of childhood maltreatment incidents. While longterm adult mental health outcomes remain issues of critical concern for researchers, recent studies have also identified the association between maltreatment and adolescent AOD use (e.g., Kilpatrick, Ruggiero, Aceirno, Saunders, Resnick, \& Best, 2003). Although ambiguity exists as to whether maltreatment is a risk factor for adolescent AOD use or vice versa, it is widely accepted that maltreatment and AOD use co-exist in adolescence (Bensley, Spieker, Van Eenwyk, \& Schoder, 1999; Kilpatrick et al., 2003).

\section{Maltreatment and AOD Use in Girls}

It has been suggested that adolescent girls report more experiences of maltreatment, including sexual, physical and emotional abuse than adolescent boys (Tubman, Montgomery, Gil, \& Wagner, 2004). With regard to types of maltreatment experienced, girls are more likely to be sexually abused than boys (Clark, Lesnick, \& Hegedus, 1997; Kilpatrick et al., 2000; Bailey \& McCloskey, 2005). The DHHS reported that girls are as high as 4 times more likely to be sexually abused as boys (DHHS, 2001). Boys are more likely to experience more physical violence than girls; however, a substantial number of adolescent girls report physical abuse, usually in conjunction with other types of maltreatment (i.e., sexual abuse and verbal abuse; Kilpatrick, et al., 2003; Titus et al., 2003). Since there have been reports of (a) gender differences in types of maltreatment experiences and (b) varying AOD use patterns associated relative to gender, 
it seems plausible that subsequent substance use patterns in maltreated adolescents will differ relative to gender as well.

In support of above notion, there is evidence pointing to varying models for the predictors of AOD use and actual AOD use patterns for adolescent boys vs. adolescent girls (NIDA, 2004). Adolescent boys who use AOD are more likely than girls to be referred to AOD abuse treatment due to their externalizing behaviors (Goldstein, Arnold, Wein, Mesiarik, Peuchold, Grisso, \& Ossman, 2003). As a result of this gender difference in treatment referral rates, the literature regarding AOD use patterns in boys is emerging, while the research regarding girls' AOD use patterns continues to lag. Because information on AOD use patterns in adolescent girls is lacking, this section of the paper focuses exclusively on the AOD use patterns in adolescent girls relative to maltreatment in an effort to advance the literature.

In one oft-cited study, Kilpatrick and colleagues (Kilpatrick et al., 2000) investigated the risk factors of adolescent AOD use. These researchers examined the effects of maltreatment, familial AOD use, and PTSD symptoms on adolescent AOD use using a national sample. Participants drawn from this national sample were 3,907 (girls, $n=1904$ ) adolescents ranging in age from 12-17, of which $15 \%$ were African-American and $8 \%$ Hispanic. First, these researchers found that girls were less likely than boys to have alcohol and marijuana abuse/dependence when controlling for other variables. However, when the girls were maltreated, they exhibited AOD abuse at younger ages than non-maltreated girls. This pattern of AOD use among girls who were maltreated was consistent with findings from Bensley et al. (1999) study, which also found that 
younger adolescents $\left(8^{\text {th }}\right.$ graders $)$ with maltreatment histories were at greatest risk for heavy alcohol use when compared to older adolescents $\left(10^{\text {th }}\right.$ and $12^{\text {th }}$ graders $)$.

Contrary to previous literature, Kilpatrick et al. (2000) did not find gender differences in the relationship between maltreatment and AOD abuse/dependence. Irrespective of forms of maltreatment experienced, maltreatment in girls and boys resulted in similar levels of AOD abuse and/or dependence. Another important finding was that African-American and Hispanic adolescents were less likely than White adolescents to have alcohol and marijuana abuse/dependence even when accounting for maltreatment histories and trauma symptoms. Again, this finding points towards differential pathways of AOD use in minority populations.

Bailey \& McCloskey (2005) investigated the pathways to AOD use in sexually abused girls using longitudinal data spanning for 9 years. The girls $(N=150)$ were on average 9.2 years old at Time 1, 14.6 years old at Time 2, and 16.4 years old at Time 3 . The sample included 36\% Hispanic girls and 5\% African-American girls; however, ethnicity was not included the analyses of the final model. Maltreatment reports were obtained from both the mothers and their daughters (Time $1 \&$ Time 2). Adolescent AOD use reports were obtained only from adolescents (Time 3). These researchers found differences in the AOD use levels in maltreated and non-maltreated adolescent girls. Eighty percent of sexually maltreated girls used marijuana, while only $41 \%$ of the nonmaltreated girls did. The trend of higher substance levels for sexually maltreated adolescent girls was also found with reports of cocaine, crystal methamphetamine, and other drug use. Consistent with the findings in the Kilpatrick et al. (2000) study, Bailey and McCloskey found that maltreatment experiences in girls are causally related to AOD 
use. They observed that reports of sexual maltreatment "both occurred and [were] measured prior to the assessment of adolescent substance use" (Bailey \&McCloskey, 2005). These studies provide support for future studies examining the links between maltreatment and AOD use. While results from both studies suggested a causal link between maltreatment and AOD use, questions remain as to whether other variables potentially mediate that relationship (e.g., trauma symptoms).

\section{Trauma Symptomology}

Clearly, some degree of trauma is a result of maltreatment experiences. Some have speculated that the link between maltreatment and AOD use is more specifically the result of the trauma involved (e.g., Kilpatrick, 2003). In this line of reasoning, trauma experiences (such as maltreatment episodes within family context) result in aversive trauma symptoms, which adolescents then "self medicate" with alcohol and/or drug use.

Recently, scholars have begun to investigate links between trauma and AOD use. For example, Giaconia, Reinherz, Hauf, Paradis, Wasserman, \& Langhammer (2000) investigated the association of trauma symptoms and AOD use in adolescents (49\% girls). Giaconia et al. (2000) found that while adolescent girls and boys were equally as likely to have experienced trauma, girls had five times greater risk of developing PTSD than their male counterparts. Moreover, they found that adolescents who use AOD are more likely than their non-AOD using counterparts to exhibit trauma symptoms; there was a frequent co-occurrence of trauma symptomology and AOD use in adolescents. Similarly, Kilpatrick et al. (2000) found that when controlling for maltreatment, PTSD symptoms were linked with marijuana and hard drug use disorders. Taken together, these findings elucidate the potential for trauma symptoms as mediating mechanisms in the 
relationship between maltreatment and AOD use. These findings also raise the question as to whether the distress from maltreatment experiences or the actual incidents of maltreatment are driving the association.

Following the findings in their first study (Kilpatrick et al., 2000) regarding the associations between maltreatment, AOD use, and post-traumatic stress disorder (PTSD) symptoms, Kilpatrick and colleagues (2003) sought to investigate the co-occurrence of these issues. Using their original sample of adolescents, they investigated co-occurring patterns of major depressive episodes (MDE), PTSD, and AOD use disorders. They found that Hispanic $(\mathrm{OR}=4.1)$ and African-American $(\mathrm{OR}=2.5)$ adolescents were more likely than White adolescents to meet the criteria for non-comorbid PTSD. These findings suggested increased risk for exposure to maltreatment for the two minority subgroups.

Kilpatrick et al. also found that sexual assault and physical assault were risk factors for both co-occurring PTSD and MDE $(\mathrm{OR}=2.43,2.76)$ and PTSD and AOD use disorders $(\mathrm{OR}=6.73,2.84)$, respectively. Girls were at greater risk for co-occurring PTSD and MDE $(\mathrm{OR}=2.56)$ than boys. For both co-occurring PTSD and MDE and PTSD and AOD use disorders, there were no ethnicity-specific effects.

Sexual assault only was found to be a risk factor for co-occurring MDE and AOD use disorders $(\mathrm{OR}=4.43)$. Being African-American vs. White was found to be a protective factor $(\mathrm{OR}=.15)$ with this association. Another key finding was the prevalence rate of AOD abuse and/or dependence (10.2\%) in girls ages 15-17. Three primary implications can be drawn from this study. First, maltreatment is linked with mental health issues and AOD use, both maladaptive outcomes. Second, sometimes these 
maladaptive outcomes do not occur in isolation. Finally, there are differential genderbased and ethnicity-based risks for maltreatment-associated mental health issues.

Kilpatrick et al. (2003) concluded with discussion of the high prevalence rate of PTSD (i.e., boys-3.7\% and girls-6.3\%) in their probability sample when compared to previous studies. Almost 200 adolescents exhibited high levels trauma symptoms and met previous 6-month PTSD criteria. Again, the notion of trauma symptoms being a critical variable in the association of adolescent AOD use and maltreatment was supported. These authors argued that while there has been substantial literature to support the association of maltreatment and AOD use in adolescents, the nature of the impact trauma symptoms remains obscure. It is possible that trauma symptoms can take on the role of mediators in the relationship between maltreatment and AOD use in African-American and Hispanic adolescent girls. Thus, this gap in knowledge provides the impetus for future research addressing this issue.

\section{Theoretical Perspectives}

Although much of the literature on adolescent AOD use and maltreatment is descriptive, there are various theoretical perspectives regarding the association between these two constructs that are helpful for interpreting findings and setting intervention goals. One theory posited in the literature suggests that AOD use in adolescence is best described by problem-behavior theory (Jessor \& Jessor, 1977). The problem-behavior theoretical proposition asserts that adolescents possess social values that influence them to engage in problem behaviors. Particular experiences may increase their involvement in problem behaviors, thus placing them at risk for maladaptive developmental outcomes. This theoretical approach includes notions of behavior under-control. There has been 
some research showing physiological links to behavior under-control. For example, childhood stressors (e.g., maltreatment) affect serotonin levels, thus increasing proneness to problem behaviors (e.g., AOD use in adolescence; Brodsky et al., 2001). Consistent with this finding, and with the view that negative experiences result in biological changes that result in problem behavior proneness, longitudinal studies have shown that maltreatment experiences precede reports of AOD use (e.g., Bailey et al., 2005). In sum, problem-behavior theoretical framework is consistent with some existent literature on the experiences of maltreatment and later AOD use in adolescent girls.

The self-medication theoretical hypothesis is a line of reasoning that complements the biological aspect of the theory of behavioral under-control. However, it includes a third variable--psychological distress or dysfunction, or in this case, trauma symptoms. The primary tenet of the self-medicating hypothesis is that the etiology of AOD use in some adolescent girls is linked with maltreatment experiences. Consistent with the stress and coping model of substance use (Wills \& Filer, 1996) girls engaging in AOD use may be trying to subdue the aversive effects of trauma symptoms following maltreatment episodes (Hallfours, Waller, Bauer, Ford, \& Halpern, 2005), which include perceived stress and/or elevated physiological responses to stress (Chassin et al., 2003). Adolescent girls may thus choose to use AOD to avoid or numb the painful effects and consequences of previous maltreatment episodes. Consistent with this rationale, some researchers believe this explanation accounts for the early onset of AOD use in adolescent girls who have experienced maltreatment and exhibited trauma symptoms (e.g., Bensley et al., 1999). 
The association between AOD use and maltreatment in adolescents is also situated in the developmental psychopathology theoretical framework. The developmental psychopathology theoretical approach takes into account development across the life span, and suggests that negative events or poor outcomes at a given stage may have a negative effect on subsequent developmental outcomes (e.g., Masten, Faden, Zucker \& Spear, 2008). Some maltreatment literature contends that maltreatment episodes precede AOD use in adolescents (e.g., Kilpatrick et al., 2003; Zucker, 2006). It is probable that this association exists due to the impaired cognitive functioning or psychopathology stemming from maltreatment experiences. Potentially, the experience of maltreatment is so traumatizing for girls that they develop mental health problems. The effects of this pathology (e.g., trauma symptoms) subsequently disrupt development along normative trajectories of adolescence. Movement from normative trajectories may increase risk and lead to an adolescents' willingness to engage maladaptive behaviors, including AOD use (Zucker, 2006).

Lastly, according to the ecological developmental theoretical approach, bidirectional influences between adolescent girls and the nested social systems in which they live must be assessed in order to fully understand developmental outcomes (Bronfenbrenner, 1986). The most immediate system, the mesosystem includes the family, peer relationships, neighborhood availability of substances, and religiosity, and each of these has been shown in the literature to impact AOD use levels in adolescent girls (Saint-John \& Crandall, 2004). The mesosytem also includes ethnic and cultural factors. Ethnic mistrust, perceived discrimination, ethnic orientation and ethnic pride have all been shown in the literature to have an effect on AOD use levels in adolescents 
(Gil, Wagner, \& Tubman, 2004). Additionally, Gil et al. found that cultural mistrust, ethnic orientation, and ethnic pride all had a significant impact on adolescent AOD treatment response. The risk and protective role, as well as amenability to AOD treatment impact of ethnic factors has not been explored in Hispanic and AfricanAmerican adolescent girls with maltreatment experiences. In sum, it is important that future treatment interventions for AOD use in maltreated adolescent girls' consider the impact of ethnicity-specific factors on treatment effectiveness.

While the theoretical approaches highlighted in this section are not exhaustive explanatory frameworks for the association of AOD use and maltreatment in adolescent girls, each of them provides some foundation for understanding the association. As reviewed here, the literature suggests that there are important links between girls' AOD use, maltreatment, and trauma symptomology. However, the precise dynamics of the relationship of these variables has not been studied, particularly in samples of AfricanAmerican and Hispanic adolescent girls. The theoretical underpinnings presented in this section are frameworks that guide the proposed investigation of these associations to derive novel explanations of girls' AOD use.

\section{Summary}

The literature outlined in this chapter revealed many critical issues. First, there is substantial literature showing an association between maltreatment experiences and AOD use in adolescents. In addition, the research has shown that trauma symptoms are factors in maltreatment and AOD use in adolescents. The shortcomings of the existing literature were also emphasized. Girls are not often exclusively included in studies investigating maltreatment and AOD use. When studies have included adolescent girls in the sample, 
they have included insignificant numbers of African-American and Hispanic girls. Consequently, there remain critical questions regarding the factors in the relationship between maltreatment experiences and AOD use.

In a review of maltreatment literature spanning more than 15 years, Kenny and McEachern (2000) asserted that more research is needed to understand the impact of maltreatment experiences among different ethnic and cultural subgroups. These researchers called for systemic approaches to maltreatment, with special consideration for the impact of ethnicity-specific factors in an effort to develop interventions that alleviate some of the negative outcomes of maltreatment experiences. To date, very little research has examined the developmental impact of maltreatment and AOD use with AfricanAmerican and Hispanic adolescent girls. This study is an attempt to add to what is known in this important area.

\section{Research Aims}

Given the scant literature concerning the association of maltreatment experiences and levels of AOD use in African-American and Hispanic girls, there is a substantiated need for empirical research on these relationships. Previous research has not inclusively investigated the potential mediating paths of abuse experiences and trauma symptoms relative to AOD use. The current study will investigate the relationship of maltreatment histories and AOD problems in adolescent girls, including links with trauma symptoms. The development of an explanatory model of these relationships is essential for the quest to acquire knowledge of how these constructs play out in adolescent girls, namely African-American and Hispanic girls. My study aimed to investigate the relationship 
between maltreatment experiences and AOD problems in African-American and Hispanic girls. Specifically, this study had the following aims:

Research Aim I. To examine the impact of maltreatment experiences and trauma symptoms on girls' AOD problems (i.e., AOD problem severity, alcohol abuse, alcohol dependency, drug abuse, and drug dependency). It was expected that maltreatment and trauma symptoms would both be positively associated with AOD problems, but that trauma symptoms would mediate the relation between maltreatment and AOD problems.

Research Aim II: To examine the impact of ethnicity-specific factors (i.e., perceived discrimination, ethnic identity, and ethnic orientation) on the relationship between maltreatment experiences and AOD use behaviors (i.e., AOD problem severity, alcohol abuse, alcohol dependency, drug abuse, and drug dependency). It was expected that ethnicity-specific factors (i.e., perceived discrimination, ethnic identity, and ethnic orientation) would moderate the relationships between maltreatment experiences, trauma symptoms and AOD problems.

In pursuing these aims, this study will illuminate four possibilities, or proposed models, regarding the potential associations of girls' maltreatment experiences, trauma symptoms, and AOD problems that have been proposed in the literature reviewed above. These four competing models are depicted in Figure 1. The first model, the Direct Effects model, displays direct effects of both trauma symptomology and actual maltreatment experiences on adolescent AOD problems. Some literature has suggested that there are functional mechanisms with both constructs that lead to the development of AOD problems among adolescent girls. The Direct Effects model is supported by the theory of problem behavior, which purports that certain personality or cognitive aspects (e.g., 
proneness to develop trauma symptoms), as well as environmental risks (e.g., maltreatment experiences) can increase involvement in problem behaviors (e.g., adolescent AOD use). This conceptual model is understudied in the AOD usemaltreatment literature for adolescents.

The second model, the Mediation Model, is consistent with both the selfmedicating hypothesis and the developmental psychopathology framework. Some literature suggests that maltreatment indirectly impacts AOD problems through trauma symptoms which in turn influence adolescent girl's development of AOD problems and/or diagnoses.

The third model, the Mediation with Interaction Effects Model is an extension of the first model. However, this model adds the moderating effect of ethnicity-specific factors at all levels of the association. While the mediated relationships can be attributed to other theories, as mentioned above, the added dimension of ethnicity-specific factors as moderators in these relationships supports the ecological developmental framework. It is plausible that the relation between maltreatment and AOD problems in adolescent girls' must be contextualized for African-American and Hispanics. Consideration of key ethnicity-specific constructs may prove to be integral to knowledge about how maltreatment impacts AOD use for adolescent girls given certain features of their context.

As reiterated often in this review, most research studies have included few, if any African-American and Hispanic adolescent girls in their samples. The lack of inclusion of ethnic-minority adolescent girls in studies exploring the relationships of these 
constructs precludes accurate positioning of moderating effects. Thus, positioning of potential moderating effects of ethnic factors remains exploratory.

The final model, the Full Model, shows the interplay of all paths shown in preceding models. It may be the case that both trauma symptoms and maltreatment experiences have a direct effect on AOD problems, but that maltreatment experiences also exhibit indirect effects as well. Additionally, there may be some moderating impact of ethnicity-specific factors on these relationships. By testing the Final Model, conclusions will be possible as to which of the relations proposed in the literature are most consistent with data obtained in this study from a sample of African-American and Hispanic adolescent girls. 


\section{CHAPTER III}

\section{METHODOLOGY}

\section{Participants}

Data for this study consisted of a subset of data from a larger NIAAA funded study, Treating Girls' Problems with Alcohol and other Drugs, (R21AA014914, PI: Montgomery). The study included 170 high-school aged adolescent girls, and was designed to investigate the efficacy of a brief motivational school-based intervention, Guided Intervention for Real Life Skills (GIRLS), for reducing girls' AOD use.

Participants in this study (1) had active parental consent; (2) agreed to participate; (3) used AOD at least 6 times within the 3 months prior to screening; (4) did not have current suicidal risk; (5) did not have psychoactive drug disorder; and (6) did not exhibit any cognitive dysfunction or developmental delay that would preclude comprehension of study questions and intervention materials.

\section{Procedures}

The girls were recruited from the Miami-Dade County Public Schools high schools involved with the grant. An overview of the project was presented to the girls at the schools and all girls were asked to submit a confidential form expressing either their interest or disinterest in participating. All interested girls received a brief eligibility screening. Following the brief screening, the girls were given a parental consent to have their parents sign. After both signed parental and participant (girls) consent forms were received, trained research interviewers administered a comprehensive computer-assisted baseline assessment to the girls including questions about their AOD use patterns and associated problems, dating relationships, mental health functioning, maltreatment 
histories, involvement in counseling services, and current emotional distress. Following the baseline assessment, the girls were randomized into the control or treatment condition. Three follow-up assessments (post, 3-month, and 6-month) were completed beginning after completion of treatment or 2 months after baseline for the control condition. To minimize attrition each girl was given a $\$ 15$ gift card to an electronic department store following each assessment.

Measures for Predictors

Childhood Trauma Questionnaire (CTQ-Short Form; Bernstein, Fink, Handelsman, Foote, Lovejoy, Wenzel, Sapareto, \& Ruggiero, 1994.) The 35-item measure assesses for frequency of maltreatment experienced by girls "while growing up." Girls were asked to respond to questions using a 5-point Likert scale ranging from never true to very often true. Some examples of questions include: "People in my family hit me so hard that it left bruises or marks on me," "People in my family said hurtful or insulting things to me," and "Someone tried to touch me in a sexual way or tried to make me touch them." The CTQ has four subscales: physical and emotional abuse, emotional neglect, sexual abuse, and physical neglect. The internal consistencies for the scales have been shown to range from .79 to .94 (Bernstein et al., 1994; Scher, Stein, Admundson, McCreary, \& Forde, 2001). Factor analytic results using data for this study suggested three subscales: physical and emotional abuse, sexual abuse, and physical and emotional neglect. The Cronbach's alpha values in this study also demonstrated good internal consistency for subscales: physical and emotional abuse $(\alpha=.81)$, sexual abuse $(\alpha=.91)$, physical and emotional neglect $(\alpha=.75)$. 
Trauma Symptom Checklist (TSC-40; Eliot \& Briere, 1996 ). The Trauma Symptom Checklist - 40 (TSC-40) assesses for frequency of symptoms associated with traumatic experiences across 6 subscales (anxiety, depression, dissociation, sexual abuse trauma index, sexual problems, and sleep disturbances). Respondents were asked to respond to symptoms experienced in the last 2 months, such as "feeling isolated from others" and "uncontrollable crying" on a 5-point scale ranging from never to extremely often. For the current study, the total scale was used to determine current level of trauma symptomology. TSC-40 has been reported to good predictive validity for traumatic experience reports (Zlotnick, Shea, Begin, Pearlstein, Simpson, \& Costello, 1996). Internal consistency values have been reported to range from .66 to .91 (Briere \& Runtz, 1998). The Cronbach's alpha values in this study also demonstrated acceptable internal consistency for subscales: dissociation $(\alpha=.67)$, anxiety $(\alpha=.71)$, depression $(\alpha=.73)$, sexual abuse trauma index $(\alpha=.65)$, sleep disturbances $(\alpha=.78)$, sexual problems $(\alpha=$ $.75)$, total scale $(\alpha=.90)$.

\section{Outcomes Measures}

Drug Use Screening Inventory-Revised (DUSI-R; Tarter \& Kirisci, 2001). The current study used the subscale of the adolescent version of the DUSI-R that assesses AOD problem severity. The DUSI-R consists of 16 -items to which girls were asked to respond yes or no to a number of dependency and abuse symptoms. Some of the questions included, "Do you have trouble resisting drugs or alcohol?" "Have you had to use more drugs or alcohol to get the effect you wanted?" In the current study, a total score was derived by summing the number of items to which girls responded affirmatively. The item assessing for veracity of responses ("Have you ever told a lie?") 
was omitted from total scale, thus total score ranged from 0 to 15 . Internal consistencies measurements have been reported to range from moderate to excellent. The adolescent version of the DUSI-R has shown good reliability and validity, and scores on the AOD DUSI-R subscale are related to alcohol and other drug use disorder diagnoses among adolescents (Tartar \& Kirisci, 2001). The Cronbach's alpha value $(\alpha=.76)$ in my study also demonstrated good internal consistency.

Composite International Diagnostic Interview (CIDI; Kessler et al., 1994 ). Girls were assessed for the presence/absence of Alcohol Abuse, Alcohol Dependence, Drug Abuse, and Drug Dependence using the Brief Michigan Composite International Diagnostic Interview (CIDI) developed by Kessler and colleagues. The Michigan CIDI has been widely used in epidemiological research and with multiple ethnic groups including Hispanics/Latinos and African-Americans (Kessler et al., 1994). The CIDI has demonstrated excellent interrater reliability (Wittchen, Robins, Cottler et al., 1991) and good test-retest reliability (Wacker, Battegay, \& Schlosser, 1990).

\section{Ethnicity-Specific Factors}

While the evaluation of ethnicity-specific factors was not of primary interest in this study, previous research has shown links between ethnic-related constructs and developmental outcomes (e.g., Gil \& Vega, 1998; Gil et al., 2004). Because two ethnicminority populations were included in the sample, it was deemed important to explore the influence of these factors in the proposed models. The measures evaluating these potential influences are listed below.

Perceived Discrimination. A measure developed by Williams (1997) was used to assess girls' perceived discrimination. The measure evaluated girls' perceptions of 
discrimination in myriad settings, such as shopping centers, police interactions, school, etc. (e.g., "You receive worse services than others at restaurants or stores"). Items were dichotomously scored (i.e., $0=$ No, $1=$ Yes). In the current study, a total score was derived by summing the number of items to which girls responded affirmatively, thus the total perceived discrimination score ranged from 0 to 15 . The measure has been used in other NIDA-funded studies and has demonstrated good construct validity and internal reliability (Vega \& Gil, 1999; Gil et al., 2004, Burrow, Tubman, \& Gil, 2007). Internal consistency values have been reported to range from about .85-.88 (Taylor \& Turner, 2002; Burrow et al., 2007). The Cronbach's alpha value $(\alpha=.73)$ in this study also demonstrated good internal consistency.

Multigroup Ethnic Identity Measure (MEIM; Phinney, 1992). The study used a 6item version of the MEIM. The MEIM evaluates individuals' perceptions of their membership, attitudes and pride in their ethnic group. Participants were asked to report the ethnic group to which they felt they were a member. Following the identification of a particular ethnic group, participants were asked to respond to questions relative to their identified ethnic group (e.g., "I am active in clubs or groups that include mostly other kids in my ethnic group"). The items were rated on a 5-point Likert scale (strongly disagree to strongly agree). The measure has been used in many different countries and with many ethnicities and has maintained its strong psychometric properties (e.g., Hispanics (Gamst, Dana, Der-Karabetian, Aragon, Arellano, \& Kramer, 2002); Zimbabweans (Worrell, Conyers, Mpofu, \& Vandiver, 2006). The Cronbach's alpha value $(\alpha=.74)$ in this study also demonstrated good internal consistency. 
Ethnic Orientation. Girls' ethnic orientation was assessed using a measure adapted from the work of Cuellar, Harris, and Jasso (1980) with Hispanics. Girls were asked to respond to eleven items evaluating their sense of ethnic pride and orientation to their respective ethnic groups (e.g., "Your ethnic heritage is important in your life.") on 5-point Likert scale (strongly disagree to strongly agree). The measure has been used with both African-Americans and Hispanics and has shown acceptable psychometric properties (Gil, Wagner, \& Tubman, 2004). The Cronbach's alpha value $(\alpha=.82)$ in this study also demonstrated good internal consistency.

Demographics. As with most studies, a set of specific questions were asked to collect background information from girls. The demographic questions in this study included questions regarding age, grade, academic status, ethnicity of girls and parents, religious affiliation, family structure, and parental education/vocation. 


\section{CHAPTER IV}

\section{RESULTS}

This study aimed to test four competing relational models accounting for the links between maltreatment experiences among girls and their AOD problems. Each of the models was evaluated using a structural equation modeling (SEM) techniques in Mplus 4.1 (Muthén \& Muthén, 2006). SEM analysis was used to estimate the direct and indirect effects of independent and mediating factors with a single indicator path analytic approach and a robust weighted least squares solution. SEM was selected over OLS regression because SEM allows for more accurate path estimates between variables by utilizing a measurement modeling technique that accounts for measurement error when estimating the paths among variables in the analysis (Byrne, 2001). Traditional multivariate methods like regression assume variables in the analysis are perfectly reliable; that is, free of measurement error. Additionally, SEM affords formal significance testing of competing models to identify the most appropriate model given the data.

Missing Data. In the current study, there were minimal amounts (i.e., $<5 \%$ ) of missing data because this study used computer-assisted data collection that disallows advancing to the next question without proper response to a previous one for many questions. When data was missing, it was due to computer malfunctions or software program errors so missing data was assumed to be missing completely at random. Additionally, this study analyzed baseline data so issues of attrition were not applicable. However, when missing data was present it was formally addressed. The study utilized Amelia statistical software (Honaker, King, \& Blackwell, 2009) to input missing data. 
The algorithm used by Amelia is superior to other imputation methods (e.g., mean imputations, median imputations) because Amelia provides imputation estimates that include elements of randomness rather than relying solely on existing patterns within the data.

Descriptive Analyses. Measures of central tendency were computed for each variable (see Table 2). Assessment of the distribution pattern of data was evaluated for violations of traditional normality assumptions. Correlation matrices were also computed for predictor variables to assess for mulitcollinearity (see Table 3).

Outlier analyses included both non-model based and model based evaluations of variable data. For non-model based univariate outliers, leverage indices for each individual were examined and an outlier was defined by leverage score four times greater than the mean leverage. No outliers were identified using this procedure. A model based or multivariate outlier analysis was conducted. This analysis involved random selection of an endogenous variable which was, in this case, DUSI total (AOD problem severity). Then using OLS regression, the selected variable was regressed onto each of other endogenous variable. Standardized $d f$ beta estimates were then examined for the predictors and intercepts for each case. Outliers were defined as the absolute value of standardized $d f$ beta scores in the excess of 1 . No outliers were identified in this study.

Power Analysis. To determine the appropriate sample size needed for structural equation modeling analyses, a limited information approach was used to obtain a rough approximation of statistical power. The limited information approach technique uses traditional power analysis software to gain a sense of sample size demands (Jaccard \& Wan, 1996). A power analysis was conducted to estimate power for a predictor that 
accounts for at least 5\% unique variance in the outcome. As will be seen later in the model, the maximum number of predictors for a multiple regression analysis was seven, but the more typical number of predictors was four. A squared multiple correlation of 0.20 was used as a basis for this power analysis, since this was lowest squared correlation observed in the modeling. Also, a 0.05 alpha level and a two-tailed test were assumed. The sample size of 170 yielded a power coefficient of .89 for linear models having either seven or four predictors. Given a medium effect size of .05 (Cohen, 1988) and one predictor for the logistic regression, a sample size of 170 yielded a power coefficient of .86. Therefore, a sample size of 170 yielded satisfactory power for the proposed analyses.

Preliminary Analyses. Ethnic group differences on the outcome variables were evaluated in order to add to what is known about these understudied groups of girls. A series of independent sample t-tests and chi-square tests were conducted to examine significant differences on key study variables for African-American and Hispanic adolescent girls (see Table 6). Hispanic girls had a significantly higher AOD problem severity scores. Additionally, significantly more Hispanic girls met the diagnosis for drug dependency than African-American girls. African-American girls reported significantly more perceived discrimination experiences and a stronger sense of ethnic identity than their Hispanic counterparts. To explore the potential for ethnic group differences in the relations between variables, the final model included analyses for a multiple group solution.

Model Fit and Evaluation. For evaluating model fit, the following indices and criteria were used. The Tucker Lewis Index (TLI) was examined and values of .95 or 
greater indicated a good model fit. The Root Mean Square Error (RMSEA) was examined and values less than .08 indicated good model fit. Finally, the $p$ value for Close fit test was examined and values greater than .05 indicated good model fit. In addition, more focused fit indices were examined. Modification indices of notable size (values of 4 or greater) were evaluated to see if there were any conceptual rationales for modifying the model in the manner suggested. Additionally, standardized residual values were evaluated. Any values greater than two were considered points of stress in the model and sources of ill fit.

Limited Information Estimation and Full Information Estimation. Because of the complexity of the proposed model and the inclusion of interaction terms, preliminary analyses were conducted using the limited information estimation approach. The limited information estimation approach included a division of the model into smaller clusters and analyses using SEM techniques. Each cluster comprised one interaction term and the two variables for which the interaction term moderated their relationship creating a justidentified model situation. The purpose of this approach was to assess the significance of each interaction term individually to make an informed decision to include or trim interaction term from the full model.

Prior to being added to the model, perceived discrimination, ethnic orientation, and ethnic identity were mean centered. Mean centering of variables was achieved by subtracting each participants' score from the mean of each variable. When including variables as interaction terms, it has been found that mean centering is a good strategy in countering any collinearity issues (Cohen \& Cohen, 1983). Following mean centering, product terms were computed for each hypothesized interaction effect; product terms 
were computed by multiplying each predictor by each ethnicity-specific variable in the system (e.g., sexual abuse X perceived discrimination).

Competing Conceptual Models. The four conceptual models presented in Figure 1 were integrated into one full model (see Figure 2) for analysis. The full model tested each of the four conceptual frameworks utilizing a characterization of different patterns of significance, such that each relational model was tested based on presence of significant path coefficients for the hypothesized relations. The following paragraphs describe how each of the four conceptual models is comprised within the full model and how significant patterns map onto either full support, partial support or no support for the four hypothesized models.

First, full support for the Direct Effects Model would be characterized by significant path coefficients for Paths A and B and non-significant path coefficients for Paths C, D, E, F. Full support for the Mediation Model would be characterized by significant path coefficients for Path A and Path C and non-significant path coefficients for Paths B, D, E, and F. Next, full support for the Mediation Model with Interaction Effects would be characterized by significant path coefficients for Paths A, C, D, and F, and Path B and Path E would be non-significant. Finally, full support for the Full Model would include significant coefficients for every path shown in Figure 2. Partial support for any of the above list models would be characterized by significance some of the key path coefficients for each model; while no support for model would be characterized by poor model fit and/or non-significance for key path coefficients. 
Model Evaluation and Modification. Following utilization of the limited information estimation approach to modeling, the full model, including all significant interaction terms, was fitted using full information estimation techniques. The overall chi square of model fit was statistically non-significant $\left(X^{2}(24)=19.05, p=.75\right.$. The Root Mean Square Error of Approximation (RMSEA) was $<.001$. The $p$ value for the test of close fit was .97. The Tucker Lewis Index (TLI) was 1.0. The standardized root mean square residual (SRMR) was .05. Inspection of residual covariance matrices revealed no ill model fit. Modification indices did not reveal any paths of theoretical or conceptual relevance. Although there was good model fit, the decision was made to systematically trim non-significant paths from the model. Paths with null effects worsen the compromised power situation of the full model, thus increasing the likelihood of Type II error. Because of the understudied nature of the relationship of these constructs among African-American and Hispanic adolescent girls, it was deemed critical that potentially significant relations be identified.

Prior to model trimming, paths for each of the four conceptual models suggested in the literature and reviewed in Chapter Two were evaluated to identify which, if any, of the models were consistent with the data in this study.

Direct Effects Model. The Direct Effects Model was characterized by significant paths between maltreatment and AOD problem severity and trauma symptoms and AOD problem severity and AOD diagnoses, such that both maltreatment and trauma symptoms were hypothesized to have positive direct effects on AOD use behaviors. The data in this study suggested partial support for this model. The paths between sexual abuse, physical and emotional abuse, and physical and emotional neglect and AOD problem severity and 
AOD diagnoses were all non-significant (Path B in Figure 2). However, level of trauma symptoms was significantly positively related to AOD problem severity and AOD diagnoses. These results suggest that maltreatment experiences alone do not directly impact problematic AOD use.

Mediation Model. The Mediation Model was characterized by significant paths between maltreatment and trauma symptoms, and trauma symptoms and AOD problem severity and AOD diagnoses. The data suggested partial support for the Mediation Model. Physical and emotional abuse was positively related to level of trauma symptoms, which in turn was positively related to AOD problem severity, alcohol abuse, alcohol dependency, drug abuse, and drug dependency. The more physical and emotional abuse girls experienced, the greater the likelihood that they qualified for a diagnosis of alcohol abuse $(\mathrm{OR}=2.14 ; 95 \% \mathrm{CI}=1.12$ to 4.12$)$, alcohol dependency $(\mathrm{OR}=2.60 ; 95 \%$ $\mathrm{CI}=1.21$ to 5.72$)$, drug abuse $(\mathrm{OR}=4.8 ; 95 \% \mathrm{CI}=2.29$ to 10.11$)$, and $/$ or drug dependency $(\mathrm{OR}=5.63 ; 95 \% \mathrm{CI}=2.54$ to 12.53$)$, and experienced greater AOD problem severity $(B=2.08, p<.05)$. Similar relationships with AOD problem severity and AOD diagnoses were not found for sexual abuse or physical and emotional neglect. These results suggest that level of trauma symptoms may mediate the relation between certain maltreatment experiences and AOD use behaviors.

Mediation Model with Interaction Effects. The Mediation Model with Interaction Effects was characterized by significant paths between maltreatment and trauma symptoms and trauma symptoms and AOD problem severity and AOD diagnoses. Additionally, this model included the moderating effects of ethnicity-specific factors on the main relational paths of the Mediation Model. The data suggested partial support for 
this model. As mentioned, physical and emotional abuse was positively related to level of trauma symptoms, which in turn was positively related with AOD problem severity and AOD diagnoses; there were no significant findings between sexual abuse and physical and emotional neglect and trauma symptoms. There was a significant interaction between sexual abuse and perceived discrimination, such that the relation between sexual abuse and level of trauma symptoms changed as a function of perceived discrimination (see Figure 4). No other interactions were significant in the model.

Full Model. The Full Model described above would be characterized by significant paths between all variables in the system (see Figure 2). Since all direct paths from maltreatment variables to AOD problems variables were found to be nonsignificant, all of these paths trimmed were trimmed from the model except the path from sexual abuse to AOD problem severity. During the limited information estimation modeling approach with the interaction terms, a significant interaction between sexual abuse and ethnic identity was found, such that the relation between sexual abuse and AOD problem severity changed as a function of ethnic identity. In an effort to explore this relationship further, the path from sexual abuse to AOD problem severity was not immediately trimmed from the model.

The revised model was then re-estimated and the overall chi square of model fit for the Full Model was statistically non-significant $\left(X^{2}(53)=66.74, \mathrm{p}<.10\right)$. The Root Mean Square Error of Approximation (RMSEA) was .04. The $p$ value for the test of close fit was .72. The Tucker Lewis Index (TLI) was .94. The standardized root mean square residual (SRMR) was .05. All indices uniformly pointed towards good model fit. 
Inspection of residuals revealed no ill-fit in the model, and no modification indices of theoretical or statistical relevance were revealed.

Table 5 displays all estimates and Figure 3 shows all significant paths for Full Model. The final model showed that maltreatment experiences did not have a significant relation with AOD problems. Rather, the effect of physical and emotional abuse on AOD problems was mediated by trauma symptomology, which had a positive direct impact on AOD problem severity. A mediated relationship was not found with sexual abuse and physical and emotional neglect. There were two significant interactions found in this model. First, perceived discrimination was a significant moderator in the relation between sexual abuse and level of trauma symptoms, such that when perceived discrimination is at its mean, the relation between sexual abuse and trauma symptoms is predicted to increase .03 points on total trauma scale (see Figure 4). When perceived discrimination is at its mean plus 1 unit, the relation between sexual abuse and trauma symptoms is predicted to increase .06 units, a little of a half of a point on total trauma scale. These results suggest that the more discrimination a girl perceives, the stronger the effect of sexual abuse on trauma symptoms.

Additionally, ethnic identity was a significant moderator in the relation between sexual abuse and AOD problem severity, such that when ethnic identity is at its mean, the relation between sexual abuse and AOD problem severity is predicted to increase .21 points on the AOD problem severity scale (see Figure 5). When ethnic identity is at its mean plus 1 unit, the relation between sexual abuse and AOD symptoms is predicted to decrease .19 points on the AOD problem severity scale. These results suggest for girls with reports of high ethnic identity, the effects of sexual abuse on AOD problem severity 
is lessened. Stated another way, these results suggest that high ethnic identity has some protective properties in the relation between sexual abuse and AOD problem severity in adolescent girls.

Multiple Group Analyses. To assess whether the relations between model constructs operated similarly between both African-Americans $(n=56)$ and Hispanics ( $n$ =114), a multiple group solution was pursued. Prior to formal evaluation, a limited information estimation approach was utilized. Using the limited information estimation approach, the final Full Model for African-Americans and Hispanics were examined separately. To achieve these separate data analytic runs, two data files were created—one for African-Americans and one for Hispanics. Structural models were analyzed for both groups. Global and focused fit indices indicated good model fit for both groups. Path estimates were examined, and informal comparisons of path estimates for both groups were made. No theoretically meaningful differences in path estimates were identified in the between-group comparisons, thus a full information estimation approach to multiple group solution was not pursued. 


\section{CHAPTER V}

\section{DISCUSSION}

My study sought to examine the relation between maltreatment experiences and AOD problems in a sample of African-American and Hispanic adolescent girls who were participants in a school-based AOD use intervention. On the basis of theory and previous research, two primary hypotheses were delineated and tested with this sample. First, it was hypothesized that maltreatment would predict AOD problems with these girls, but that trauma symptoms would mediate the relation between maltreatment and AOD problems. Second, it was hypothesized that perceived discrimination, ethnic identity and ethnic orientation would moderate the maltreatment-AOD problem relation. Previous research has shown these constructs to be related to AOD use among adolescents (Gil, Wagner, \& Tubman, 2004). Because empirical investigation of ethnicity-specific factors as moderators in the relation between maltreatment and trauma symptoms and trauma symptoms and AOD problems is understudied area in research, positioning of the moderated effects remained exploratory.

\section{Maltreatment and AOD Problems}

Previous research has shown causal pathways in the relationship between maltreatment and AOD use (Kilpatrick et al., 2000). More specifically, studies have found that these two constructs are temporally linked with adolescent girls in that maltreatment experiences result in subsequent engagement in AOD use (Bailey \&McCloskey, 2005). However, the results in this study did not suggest a direct relation between maltreatment and AOD problems with adolescent girls. 
Much of the existing empirical knowledge on how maltreatment experiences impact AOD use with girls has used samples of adult women who retrospectively recall their maltreatment experiences (e.g., MacMillan et al., 2001; Thompson, Kaslow, Lane, \& Kingree, 2000). These women report their earliest recollection of maltreatment and their earliest recollection of AOD use or AOD problems to aid researchers in theory development around these constructs. The elapsed time between maltreatment episodes and reporting precludes evaluation of critical temporally-linked developmental and psychological constructs in this relationship. Thus, researchers are forced to test partial models, and as a result, theories are built upon limited information and actual processes and relations may be obscured. In my study, another significant variable in the maltreatment and AOD problems relationship, trauma symptomology, was added to the conceptual model. Using a statistical approach which accounted for all parts of the model simultaneously, the impact of maltreatment on AOD problems was not found to be significant in the context trauma symptoms, which better explained the variation in AOD problem severity reported by girls.

\section{Trauma Symptoms and AOD Problems}

Trauma symptoms are thought to be the key link in understanding the relationship between maltreatment experiences and AOD use (Kilpatrick, 2003). It has been posited in the literature that engaging in AOD use may help girls cope with trauma symptoms resulting from maltreatment episodes (Hallfours, Waller, Bauer, Ford, \& Halpern, 2005). Many believe the mood-altering effects of AOD help relieve the persistent, intrusive thoughts and feelings associated with past traumas. Similarly, some researchers contend that the experience of being abused is so traumatic for some adolescent girls that they 
develop cognitive dysfunction, i.e., inability to evaluate risks, inability form positive selfconcept (Briere \& Elliot, 1994), and behavior under-control (Brodsky et al., 2001 ). The cognitive dysfunction presents a risk for girls to engage in maladaptive behaviors to development (e.g., AOD problems in adolescence).

The results of this study were consistent with frameworks that propose that trauma symptoms mediate the maltreatment-AOD problems relation. My study's findings demonstrated that certain forms of maltreatment (physical and emotional abuse) were significantly and positively associated with trauma symptoms, and trauma symptoms were significantly and positively associated with AOD problems. Girls who experienced physical and emotional abuse were more likely to exhibit higher levels trauma symptoms and subsequently more likely to have more severe AOD problems than girls who were not maltreated. With respect to DSM-IV diagnosis, girls with higher trauma symptoms were significantly more likely to meet criteria for AOD abuse and dependencies than non-maltreated girls in this study, with as much as 2.14, 2.6, 4.8 and 5.63 times greater odds for alcohol abuse, alcohol dependence, drug abuse and drug dependence, respectively.

Substantial research has maintained that untreated victims of childhood maltreatment experience abuse related trauma symptoms for extended periods of time (Stevenson, 1999; Widom, 1999; Lansford, Dodge, Petit, Bates, Crozier, \& Kaplow, 2002;). In some cases, maltreatment-associated trauma symptoms have been found to extend into adulthood (Thompson, Kaslow, Lane, \& Kingree, 2000). My study captured girls' maltreatment histories, but the recency of maltreatment experiences was not evaluated. In contrast, the presence of current trauma symptoms (i.e., experienced within 
the last two months) was evaluated. While many potential traumagenic factors were not examined in this study, it can be postulated that the significant relationship between maltreatment and current trauma symptoms provides some evidence of the chronicity of maltreatment effects.

Impact of Ethnicity-Specific Factors

Hispanic girls scored significantly higher than African-American girls on the AOD problem severity scale and more frequently met criteria for drug dependence. These findings were consistent with national data on reported ethnic group differences (Johnston, O’Malley, Bachman, \& Schlenberg, 2008), which reveal that Hispanic adolescents use AOD at higher rates than African-American adolescents.

Beyond group differences, this study aimed to examine the effect of ethnicityspecific constructs on the relation between maltreatment, trauma symptoms, and AOD problems. Specifically, the moderating effects of perceived discrimination, ethnic orientation, and ethnic identity were evaluated. Some ethnicity-related constructs were found to be impactful in the mediated relation between maltreatment and AOD problems. For example, perceived discrimination significantly moderated the relation between sexual abuse and trauma symptoms. The more perceived discrimination a girl exhibited, the greater the effect of sexual abuse on trauma symptoms. Perceived discrimination has been shown in the literature to be linked to both physical and mental issues in ethnicminorities (e.g., Williams, et al. 1997). In essence, perceived discrimination is a chronic stressor for many African-American and Hispanic girls and its effects add to the existing stressful and traumatic events in these girls' lives. In this study, perceived discrimination 
worsened the impact of impact of sexual abuse on trauma symptomology among sexually abused girls.

The variable of ethnic orientation (i.e., specific group affiliation) did not moderate any model effects. However, ethnic identity (i.e., perception of self as group member) was a significant moderator in this study, such that as ethnic identity increased, the effect of sexual abuse on AOD problems was lessened. Essentially, ethnic identity acted as a protective mechanism in this relation. While these findings have not been explored in maltreatment-AOD use research, the notion of ethnic identity having protective properties is not novel. Marsiglia and colleagues (2001) found that ethnicityspecific variables were significant predictors of drug use patterns among a sample of adolescent boys and girls, including African-Americans and Hispanics. Both ethnic identity and ethnic pride/orientation were protective factors against drug use for Hispanics and African-Americans. These findings underscore the importance of including constructs that examine different contextual elements when studying ethnicminority populations. Because research on maltreatment and AOD use among AfricanAmerican and Hispanic adolescents is scant, more work is needed to fully elucidate the importance of ethnicity-specific variables in this area.

\section{Generalizability of Study Findings}

The results found in the current study add to the existing literature on maltreatment and AOD problems among adolescent girls. However, the generalizability of the results of the current study may be called into question. The associations found between maltreatment experiences, trauma symptoms, and AOD problems among adolescent girls may not generalize to all adolescent girls. For example, my study 
sampled high-school age adolescent girls. Differential developmental markers, familial contexts, and interpersonal relationships exist for adolescents in middle school, high school and college due to the unique developmental phases. Potentially, differential patterns of the associations between maltreatment experiences, trauma symptoms, and AOD problems may also exist for adolescent girls depending on which phase of development they are in.

On the contrary, one could also argue that there is a great deal of homogeneity that exists among experiences of maltreatment in childhood and adolescence. Much the adult maltreatment literature has showed that maltreatment is a deleterious act, and that even in the face of resilience, maltreatment has a negative impact on individuals who experience it (e.g., Mulvihill, 2005; Watts-English, Fortson, Gibler, Hooper, \& De Bellis, 2006). While not all adolescent girls who have been maltreated would exhibit AOD problems, the findings in this study regarding the association between maltreatment and AOD problems may be generalized to many adolescent girls, particularly AfricanAmerican and Hispanic adolescent girls.

\section{Implications}

The primary aim of my study was to evaluate association between maltreatment and AOD problems among adolescent girls. However, the frequency of abuse reported bears mentioning, and the results of frequency analyses revealed some shocking findings regarding abuse among girls in this study. Sixty percent of girls reported histories of emotional abuse, $37 \%$ reported physical abuse, $36 \%$ reported emotional neglect, $20 \%$ reported sexual abuse, and $2 \%$ reported physical neglect. While the percentages of abuse experienced by adolescent girls in this study are alarming, some research has suggested 
that there exists gross underreporting of abuse experiences among adolescents (Sanders $\&$ Becker-Lausen, 1995). Sexual abuse occurring in childhood and adolescence is one of the most serious forms of abuse (Boney-McCoy \& Finkelhor, 1995), and it goes unreported more often than other forms of abuse (Sauzier, 1989). When sexual abuse is reported, it is usually a delayed disclosure of five years or more (Smith et al., 2000). If reports are accurate and maltreatment is occurring fairly frequently among female adolescent substance users, then the development of treatment models for victimized girls is warranted (Najavits, 2002).

The adult literature has shown that women who experienced childhood maltreatment were less likely to successfully complete AOD treatment than men (Gutierres \& Todd, 1997). Similar patterns may be found in future studies with adolescent girls. Adolescent AOD use interventions may prove to be inadequate for abused individuals if they are not combined with therapy specifically targeting maltreatment experiences.

For many adolescent girls, the use of AOD is their primary coping defense against internalizing symptoms (e.g., trauma symptoms, depression, and anxiety) associated with maltreatment experiences. These abused girls may be ill-equipped to handle the emergence of their internalizing symptoms in the absence of AOD. Some girls may feel the need to reengage in AOD use to lessen the effects of internalizing symptoms. Other girls may experience an increase in their maltreatment-related symptoms, yet others may exercise temporary avoidance or cognitive dissociation to cope in the absence of AOD. None of these coping methods are adaptive or effective long-term. Ideally, future interventions would target both AOD use and maltreatment experiences concurrently 
(Amaro, Larson, Gampel, Richardson, Savage, \& Wagler, 2005; Najavits, 2002).

Research has shown that without proper intervention, the effects of maltreatment experiences can endure across development (Boney-McCoy \& Finkelhor, 1995).

Interventions addressing AOD use and maltreatment concurrently with victimized girls may hold promise for promoting adaptive functioning and positive development for these girls.

Additionally, the findings of this study had implications for more cultural and ethnicity sensitive approaches to treatment. For example, the results of this study showed that girls' perceptions of discrimination exacerbated the effects of maltreatment on trauma symptoms, which yielded more AOD problems. On the other hand, for girls with a strong sense of ethnic identity, the effects of maltreatment on AOD problems were lessened. In a recent review, Toth \& Cicchetti (2006) recommended that future interventions consider the role of ethnicity and culture in the development of effective treatment. Without any attention to the role of ethnicity-specific variables in the treatment of maltreatment and AOD problems, many African-American and Hispanic adolescent girls may not receive the full benefits of treatment. In the future, ethnicity-specific risk and protective factors (e.g., ethnic-identity and perceived discrimination) should be screened for prior to and integrated into interventions for maltreated African-American and Hispanic adolescent girls with AOD problems.

\section{Limitations and Future Directions}

As with any research study, the current study is not without its limitations, and implications for directions that future studies should take. First, all data used in this study was captured using measures of self-report; thus the presence of measurement error in the 
final model is probable. Due to potential measurement error, all path coefficients found in this study should be interpreted with caution. Another methodological limitation in this study was the abbreviation of some of the measures used. In an effort to reduce participant burden, some measures utilized in this study were shortened to include fewer items (e.g., MEIM). While the abbreviated versions of these measures showed acceptable reliability estimates, future studies should, wherever possible, utilize established versions of measures that have been shown to be reliable and valid with adolescents.

In my study, one of the five items comprising the physical abuse scale queried corporal punishment experiences ("I was punished with a belt, board, a cord, or some other hard object."). The issue of corporal punishment in the context of cultural values and norms is an area of persistent debate (Gershoff, 2002). Corporal punishment is frequently utilized in some African-American and Hispanic communities and is perceived as a normative parenting behavior (Pinderhughes, 2000). Nonetheless, corporal punishment has been known to cross boundaries of discipline into abuse (see Gershoff, 2002). My study did not disentangle the act of corporal punishment from physical abuse. Thus, findings regarding physical abuse found in this study should be interpreted in light of the need for a more culturally nuanced definition of abuse.

Another methodological shortcoming of this study was the evaluation of maltreatment. Maltreatment experiences were evaluated using the CTQ, a well-validated outcome tool, and informative results using the CTQ were established. However, specific and integral facets regarding maltreatment experiences were omitted. When investigating maltreatment histories, future studies should aim to capture more 
comprehensive reports of maltreatment. Optimally, one would account for characteristics such as recurrence or length of maltreatment; constellations of maltreatment experiences (sexual and physical abuse vs. physical and verbal abuse); and relationship of the adolescent to perpetrator.

Finally, there may be intra-group differences on many variables — between Hispanic groups and between groups of African descent - that might come into play in studies evaluating maltreatment, trauma, ethnic identity, perceived discrimination and AOD use and problems. Future studies should specifically seek samples that are large enough to permit conclusions about these relations, which can in turn provide the foundation for interventions that identify what works, and for whom (Kramer, Wilson, Fairburn, \& Agras, 2002).

\section{Conclusions}

My study adds to extant knowledge on the relation between maltreatment and AOD problems among adolescent girls in many key ways. First, evidence of a meditational model on the relation between maltreatment and AOD problems was found. Previously, maltreatment and AOD use have been found to have a significant association. More recently, however, empirical work has been undertaken and has shown that the presence of trauma symptoms is a mediator in that relation. The results of this study provide additional support for that body of research.

Second, the sample utilized in this study comprised a nonclinical population of adolescent girls. Previous work in this area has included samples of women who provided retrospective reports of maltreatment experiences. When adolescents have been included in studies, they have been primarily clinical samples of youth. Finally, this 
study included only African-American and Hispanic adolescent girls, two under-studied ethnic groups in maltreatment literature. The results of this study provided a foundation for future investigations on the risk and protective effects of ethnicity-related constructs on the relations between maltreatment, trauma symptoms, and AOD use in adolescent girls. In sum, all of the contributions of this study provide a framework for both researchers and clinicians to refine and reconsider how they should address issues of AOD use and maltreatment with adolescents. As maltreatment and AOD use continue to persist among adolescents, the work in this domain continues to require refinement. 


\section{REFERENCES}

Amaro, H., Blake, S.M., Schwartz, P.M., \& Flinchbaugh, L.J. (2001). Developing theory-based substance use prevention programs for young adolescent girls. Journal of Early Adolescence, 21, 256-293.

Amaro, H., Larson, M.J., Gampel, J., Richardson, E. Savage, A., \& Wagler, D. (2005). Racial/ethnic differences in social vulnerability among women with co-occurring mental health and substance abuse disorders: Implications for treatment services. Journal of Community Psychology, 33, 495-511.

Bailey, J.A. \& McCloskey, L.A. (2005). Pathways to adolescent substance use among sexually abused girls. Journal of Abnormal Child Psychology, 33, 39-53.

Bensely, L.S., Spieker, S.J., Van Eenwyk, J. \& Schoder, J. (1999). Self-reported abuse history and adolescent problem behaviors. II. Alcohol and drug use. Journal of Adolescent Health, 24, 173-180.

Bernstein, D.P., Fink, L., Handelsman, L., Foote, J., Lovejoy, M., Wenzel, K., Sapareto, E., Ruggiero, J. (1994). Initial reliability and validity of a new retrospective measure of child abuse and neglect. American Journal of Psychiatry, 151, 11321136.

Boney-McCoy, S. \& Finkelhor, D. (1995). Psychological sequelae of violent victimization in a national youth sample. Journal of Consulting and Clinical Psychology, 63, 726-736.

Boney-McCoy, S. \& Finkelhor, D. (1996). Is victimization related to trauma symptoms and depression after controlling for prior symptoms and family relationships? A longitudinal, prospective study. Journal of Consulting and Clinical Psychology, 64, 1406-1416.

Briere, J.N., \& Elliott, D.M. (1994). Immediate and long-term impacts of child sexual abuse. The Future of Children, 4, 54-69.

Brodsky, B.S., Oquendo, M., Ellis, S.P., Haas, G.L., Malone, K.M. \& Mann, J.J. (2001). The relationship of childhood abuse to impulsivity and suicidal behavior in adults with major depression. American Journal of Psychiatry, 158, 1871-1877.

Bronfenbrenner, U. (1986). Ecology of the family as a context for human development: Research perspectives. Developmental Psychology, 22, 723-742.

Browne, A. \& Finkelhor, D. (1986). The impact of child sexual abuse: A review of the research. Psychological Bulletin, 99, 66-77. 
Burrow, A.L., Tubman, J.G., \& Gil, A.G. (2007). Heterogeneity in patterns of sexual risk taking behaviors among African-American youth: Associations with general and race specific factors. Journal of Community Psychology, 35, 447-462.

Byrne, B.A. (2001). Structural equation modeling with AMOS: Basic concepts, applications, and programming. Mahwah, NJ: Lawrence Erlbaum Associates.

Bryant, A.L., Schulenberg, J.E., O’Malley, P.M., Bachman, J.G.,\& Johnston, L.D. (2003). How academic achievement, attitude and behaviors related to the course of substance use during adolescence: A 6-year, multiwave national longitudinal study. Journal of Research on Adolescence, 13, 361-397.

Chassin, L., Ritter, J., Trim, R. S.. \& King, K. M. (2003). Adolescent substance use disorders. In E. J. Marsh \& R. A. Barkley (Eds.), Child psychopathology $\left(2^{\text {nd }}\right.$ ed.), pp 317-385. New York: Guilford Press.

Clark, D.B., Lesnick, L., \& Hegedus, A.M. (1997). Traumas and other adverse life events in adolescents with alcohol abuse and dependence. Journal of the American Academy of Child and Adolescent Psychiatry, 36, 1744-1751.

Cohen, J. (1988). Statistical power analysis for the behavioral sciences $\left(2^{\text {nd }}\right.$ ed.). Hillsdale, NJ: Lawrence Earlbaum Associates.

Cohen, J. \& Cohen, P. (1983). Applied multiple regression/correlation analysis for behavioral analysis. ( $2^{\text {nd }}$ ed.). Hillsdale, NJ: Erlbaum.

Cuellar, I., Harris, L.C., \& Jasso, R. (1980). An acculturation scale for Mexican American normal and clinical populations. Hispanic Journal of Behavioral Science, 2, 199-217.

Dakof, G.A., Tejeda, M., \& Liddle, H.A. (2001). Predictors of engagement in adolescent drug abuse treatment. Journal of American Academy of Child and Adolescent Psychiatry, 40, 274-281.

Elliot, D.M. \& Briere, J. (1992). Sexual abuse and trauma among professional women: Validating the Trauma Symptom Checklist - 40 (TSC-40). Child Abuse and Neglect, 16, 391-398.

Ely, M., Hardy, R., Longford, N. T., \& Wadsworth, M. E. (1999). Gender differences in the relationship between alcohol consumption and drink problems largely accounted for by body water. Alcohol and Alcoholism, 34, 894-902.

Fergusson, D.M., Woodward, L.J. (2000). Educational, psychosocial and sexual outcomes of girls with conduct problems in early adolescence. Journal of Child Psychology and Psychiatry, 41, 779-792. 
Gamst, G., Dana, R.H., Der_Karabetian, A., Aragón, M., Arellano, L.M., Kramer, T. (2002). Effects of Latino acculturation and ethnic identity on mental health outcomes. Hispanic Journal of Behavioral Sciences, 24, 479-504.

Gershoff, E.T. (2002). Corporal punishment by parents and associated child behaviors and experiences: A meta-analytic and theoretical review. Psychological Bullentin, $128,539-579$.

Giaconia, R.M., Reinherz, H.Z., Hauf, A.C., Paradis, A.D., Wasserman, M.S., \& Langhammer, D.M. (2000). Comorbidity of substance use and post-traumatic stress disorders in a community sample of adolescents. American Journal of Orthopsychiatry, 70, 253-262.

Gil, A.G., Wagner, E.F. \& Tubman, J.G. (2004). Culturally sensitive substance abuse intervention for Hispanic and African-American adolescents: Empirical examples from the alcohol treatment targeting adolescents in need (ATTAIN) project. Addiction, 9(Suppl. 2), 140-150.

Godley, M.D., Kahn, J.H., Dennis, M.L., Godley, S.H., \& Funk, R.R. (2005). The stability and impact of environmental factors on substance use and problems after adolescent outpatient treatment for cannabis abuse or dependence. Psychology of Addictive Behaviors, 19(1), 62-70.

Goldstein, N.E., Arnold, D.H., Weil, J., Mesiarik, C.M., Peuschold, D., Grisso, T., \& Osman, D. (2003). Comorbid symptom patterns in female juvenile offenders. International Journal of Law and Psychiatry, 26, 565-582.

Grella, C.E. \& Joshi, V. (2003). Treatment processes and outcomes among adolescents with a history of abuse who are in drug treatment. Child Maltreatment, 3, 7-18.

Gutierres, S.E. \& Todd, M. (1997). The impact of childhood abuse on treatment outcomes of substance users. Professional Psychology: Research and Practice, $28,348-354$.

Hallfours, D.D. Waller, M.W. Bauer, D. Ford, C.A. \& Halpern, C.T. (2005). Which comes first in adolescence-sex and drugs or depression? American Journal of Preventive Medicine, 29, 163-170.

Honker, J., King, G, \& Blackwell, M. (2009). Amelia II: A program for missing data. [Computer software and manual]. Retrieved from http:/gking.harvard.edu/amelia/

Jaccard, J. (1998). Interaction effects in factorial analysis of variance. Newbury Park, CA: Sage. 
Jaccard, J. \& Guilamo-Ramos, V. (2002). Analysis of variance frameworks in clinical child and adolescent psychology: Basic issues and recommendations. Journal of Clinical Child and Adolescent Psychology, 31, 130-146.

Jaccard J. \& Wan, C. K. (1996). LISREL Approaches to Interaction Effects on Multiple Regression. Thousand Oaks, CA: Sage.

Jessor, R. \& Jessor S.L. (1977). Problem behavior and psychological development: A longitudinal study of youth. New York: Academic Press.

Johnson, P. B., \& Richter, L. (2002). The relationship between smoking, drinking, and adolescents' self-perceived health and frequency of hospitalization: Analyses from the 1997 National Household Survey on Drug Abuse. Journal of Adolescent Health, 30, 175-183.

Johnston, L. D., O’Malley, P. M., Bachman, J. G., \& Schulenberg, J. E. (2007). Monitoring the Future national survey results on drug use, 1975-2006: Volume I, Secondary school students (NIH Publication No. 07-6205). Bethesda, MD: National Institute on Drug Abuse.

Johnston, L. D., O’Malley, P. M., Bachman, J. G., \& Schulenberg, J. E. (2008). Monitoring the Future national results on adolescent drug use: Overview of key findings, 2007 (NIH Publication No. 08-6418). Bethesda, MD: National Institute on Drug Abuse.

Kenny, M.C. \& McEachern, A.G. (2000). Racial, ethnic, and cultural factors of childhood sexual abuse: A select review of the literature. Clinical Psychology Review, 20, 905-922.

Kessler, R.C., McGonagle, K.A., Zhao, S., Nelson, C.B., Hughes, M., Eshleman, S. et al. (1994). Lifetime and 12-month prevalence of DSM-III-R psychiatric disorder in the United States: Results from the National Comorbidity Survey. Archives of General Psychiatry, 51, 8-19.

Kilpatrick, D.G., Acierno, R., Saunders, B., Resnick, H.S., Best, C.L. \& Schnurr, P.P. (2000). Risk factors for adolescent substance abuse and dependence: Data from a national sample. Journal for Consulting and Clinical Psychology, 68, 19-30.

Kilpatrick, D.G., Ruggiero, K.J., Aceirno, R., Saunders, B., Resnick, H.S., \& Best, C.L. (2003). Violence and risk of PTSD, major depression, substance abuse/dependence, and comorbidity: Results from the national survey of adolescents. Journal of Consulting and Clinical Psychology, 71, 692-700. 
Kramer, H.C., Wilson, T., Fairburn, C.G., \& Agras, W.S. ( 2002). Mediators and moderators of treatment effects in randomized clinical trials. Archives of General Psychiatry, 59, 877-883.

Lansford, J.E., Dodge, K.A., Petit, G.S., Bates, J.E., Crozier, J., \& Kaplow, J. (2002). A 12-year prospective study of the long-term effects of early child physical maltreatment on psychological, behavioral, and academic problems in adolescence. Archives of Pediatrics and Adolescent Medicine, 156, 824-830.

Lipschitz, D.S., Rasmusson, A.M., Anyan, W., Cromwell, P. \& Southwick, S.M. (2000). Clinical and functional correlates of posttraumatic stress disorder in urban adolescent girls at a primary clinic. Journal of American Academy of Child and Adolescent Psychiatry, 39, 1104-1111.

Locke, T.F. \& Newcomb, M.D. (2003). Childhood maltreatment, parental alcohol/drug related problems, and global parental dysfunction. Professional Psychology: Research and Practice, 34, 73-79.

MacCallum, R. C., Browne, M.W. \& Cai, L. (2006) Testing differences between nested covariance structure models: power analysis and null hypotheses. Psychological Methods, 11, 19-35.

MacMillan, H.L., Fleming, J.E., Streiner, D.L., Lin, E., Boyle, M.H. Jamieson, E. et al. (2001). Childhood abuse and lifetime psychopathology in a community sample. American Journal of Psychiatry, 158, 1878-1883.

Marsiglia, F.F., Kulis, S., \& Hecht, M.L. (2001). Ethnic labels and ethnic identity as predictors for drug use among middle school students in the southwest. Journal of Research on Adolescece, 11, 21-48.

Masten, A. S., Faden, V. B., Zucker, R. A. and Spear, L. B.(2008). Underage Drinking: A Developmental Framework. Pediatrics, 121 (Supplement), pp. S235-S251.

Miller-Perrin, C.L. \& Perrin, R.D. (1999). Child maltreatment: An introduction. Newbury Park, CA: Sage.

Mulvihill, D. (2005). The health impact of childhood trauma: An interdisciplinary review, 1997-2003. Issues in Comprehensive Pediatric Nursing, 28, 115-136.

Muthén, L.K. \& Muthén, B.O. (2006). Mplus User's Guide. Fourth Edition. Los Angeles, CA: Muthen \& Muthen.

Najavits, L. M. (2002). Seeking safety: A treatment manual for PTSD and substance abuse. New York: Guilford. 
Newcomb, M. D., \& Bentler, P. M. (1987). The impact of late adolescent substance use on young adult health status and utilization of health services: A structuralequation model over four years. Social Science and Medicine, 24, 71-82.

Pinderhuges, E.E., Dodge, K.A., Bates, J.E., Pettit, G.S., \& Zelli, A. (2000). Discipline responses: Influences of parents' socioeconomic status, ethnicity, beliefs about parents, stress, and cognitive-emotional processes. Journal of Family Psychology, 14, 380-400.

Rogler, L.H. (1999). Methodological sources of cultural insensitivity in mental health research. American Psychologist, 54, 424-433.

Saint-John, G. \& Crandall, L.E. (2004). Ethnic difference in the salience of risk and protective factors for alcohol and marijuana: Findings from a statewide study. Journal of Ethnicity in Substance Abuse, 3, 11-27.

Sanders, B., \& Becker-Lausen, E. (1995). The measure of psychological maltreatment: Early data on the Child Abuse and Trauma Scale. Child Abuse and Neglect, 19, 315-323.

Sauzier, M. (1989). Disclosure of child sexual abuse: For better or worse. Psychiatric Clinics of North America, 12, 455-469.

Shin, S., Edwards, E.M., Heeren, T. (2009). Child abuse and neglect: Relations to adolescent binge drinking in the national longitudinal study of Adolescent Health (AddHealth) Study. Addictive Behaviors, 34, 277-280.

Silva, R.R., Alpert, M., Munoz, D.M., Singh, S., Matzner, F. \& Dummit, S. (2000). Stress and vulnerability to posttraumatic stress disorder in children and adolescents. American Journal of Psychiatry, 157, 1229-1235.

Smith, C.A., Ireland, T.O. \& Thornberry, T.P. (2005). Adolescent maltreatment and its impact on young adults' antisocial behavior. Child Abuse and Neglect, 29, 10991119.

Smith, D.W., Letourneau, E.J., Saunders, B.E., Kilpatrick, D.G., Resnick, H.S., \& Best, C.L. (2000). Delay in disclosure of childhood rape: Results from a national survey. Child Abuse and Neglect, 24, 273-287.

Stevenson, J. (1999). The treatment of long-term sequelae of child abuse. Journal of Child Psychology and Psychiatry, 40, 89-111.

Sue, S. (1999). Science, ethnicity, and bias, where have we gone wrong? American Psychologist, 54, 1070-1077. 
Tarter, R.E. \& Kirisci, L. (2001). Validity of the Drug Use Screening Inventory for predicting DSM-III-R substance use disorder. Journal of Child and Adolescent Substance Abuse, 10, 45-53.

The National Center on Addiction and Substance Abuse (CASA) at Columbia University. (2003). The Formative Years: Pathways to Substance Abuse Among Girls and Young Women Ages 8-22. New York: The National Center on Addiction and Substance Abuse (CASA) at Columbia University.

Thompson, M.P., Kaslow, N.J., Lane, D.B., \& Kingree, J.B. (2000). Childhood maltreatment, PTSD, and suicidal behavior among African-American females. Journal of Interpersonal Violence, 15, 3-15.

Titus, J.C., Dennis, M.L., White, W.L., Scott, C.K., \& Funk, R.R. (2003). Gender differences in victimization severity and outcomes among adolescents treated for substance abuse. Child Maltreatment, 8, 19-35.

Toth, S.L. \& Cicchetti, D. (2006). Promises and possibilities: The application of research in the area of child maltreatment to policies and practices. Journal of Social Issues, 62, 863-880.

Tubman, J.G., Montgomery, M.J., Gil, A.G., \& Wagner, E.F. (2004). Abuse experiences in a community sample of young adults: Relations with psychiatric disorders, sexual risk behaviors, and sexually transmitted diseases. American Journal of Community Psychology, 34, 147-162.

U.S. Department of Health and Human Services, Administration on Children, Youth and Families. (2001). Child Maltreatment 1999. Washington, D.C.: U.S. Government Printing Office.

U.S. Department of Health and Human Services, Administration on Children, Youth and Families. (2005). Child Maltreatment 2003. Washington, D.C.: U.S. Government Printing Office.

U.S. Department of Health and Human Services, Administration on Children, Youth and Families. (2008). Child Maltreatment 2006. Washington, D.C.: U.S. Government Printing Office.

Vega, W.A. \& Gil, A.G. (1998). Drug use and ethnicity in early adolescence. New York: Plenum Press.

Vega, W.A., \& Gil, A.G. (1999). A model for explaining drug use behavior among Hispanic adolescents. Drugs \& Society, 14, 57-74. 
Wacker, H. Battegay, R., Mullejans, R. \& Schlosser, C (1990). Using CIDI-C in the general population. In C.N. Stefains, A.D. Rabavilas, \& C.R. Soldatos (Eds.), Psychiatry: A world perspective (pp. 138-143). New York: Elsevier.

Watts-English, T., Fortson, B.L., Gibler, N., Hooper, S.R., \& De Bellis, M.D. (2006). The psychobiology of maltreatment in childhood. Journal of Social Issues, 62, 717-736.

Whaley, A.L. (2002). Psychometric analysis of the cultural mistrust inventory with a Black psychiatric inpatient sample. Journal of Clinical Psychology, 58, 383-396.

Widom, C.S. (1999). Posttraumatic stress disorder in abused and neglected children grown up. American Journal of Psychiatry, 156, 1223-1229.

Williams, D.R., Yan, Y., Jackson, J.S., \& Anderson, N.B. (1997). Racial differences in physical and mental health: Socio-economic status, stress, and discrimination. Journal of Health Psychology, 2, 335-351.

Wills, T. A., \& Filer, M. (1996). Stress-coping model of adolescent substance use. In T. H. Ollendick \& R. J. Prinz (Eds.), Advances in clinical child psychology (Vol 18), pp. 459-481. New York: Plenum Press.

Windle, M. (1994). Substance use, risky behaviors, and victimization among a U.S. national sample. Addiction, 89, 175-182.

Wittchen, H.U., Robins, L.N., Cottler, L.B., Sartorius, N., Burke, J.D., \& Regier, D. (1991). Cross-cultural feasibility, reliability and sources of variance of the Composite International Diagnostic Interview (CIDI), The Multicentre WHO/ADAMHA field trials. Bristish Journal of Psychiatry, 159, 645-653.

Worrell, F.C., Conyers, L.M., Mpofu, E., \& Vandiver, B.J. (2004). Multigroup ethnic identity measure scores in a sample of adolescents from Zimbabwe. Identity: An International Journal of Theory and Research, 6, 35-59.

Wright, J., Friedrich, W., Cinq-Mars, C., Cyr, M., \& McDuff, P. (2004). Self-destructive and delinquent behaviors of adolescent female victims of child sexual abuse: Rates and covariates in clinical and nonclinical samples. Violence and Victims, 19, 627-643.

Zlotnick, C., Shea, M.T., Begin, A. Pearlstein, T. Simpson, E., Costello, E. (1996) The validation of the Trauma Symptom Checklist-40 (TSC-40) in a sample of inpatients. Child Abuse and Neglect, 20, 503-510. 
Zucker, R A. (2006). Alcohol use and the alcohol use disorders: a developmental biopsychosocial formulation covering the life course. In: Cicchetti D, Cohen DJ, eds. Developmental psychopathology, Vol 3: Risk, disorder, and adaptation. 2nd ed. (pp. $620-656)$. New York, NY: Wiley. 
APPENDICES 
Table 1.

Demographic Data

\begin{tabular}{|c|c|c|}
\hline Variables & $n$ & $\%$ \\
\hline \multicolumn{3}{|l|}{ Country of birth } \\
\hline US born & 124 & 72.9 \\
\hline Foreign born & 46 & 27.1 \\
\hline \multicolumn{3}{|l|}{ Current grade } \\
\hline Ninth & 39 & 22.9 \\
\hline Tenth & 64 & 37.6 \\
\hline Eleventh & 41 & 24.1 \\
\hline Twelfth & 26 & 15.3 \\
\hline \multicolumn{3}{|l|}{ Ever repeated a grade } \\
\hline Yes & 46 & 27.1 \\
\hline No & 124 & 72.9 \\
\hline \multicolumn{3}{|l|}{ Family structure } \\
\hline Single parent & 79 & 46.5 \\
\hline Two parent or blended family & 91 & 53.5 \\
\hline \multicolumn{3}{|l|}{ Highest education level achieved by mother } \\
\hline Less than 7 years of school & 6 & 3.5 \\
\hline Completed junior high & 2 & 1.2 \\
\hline Partial high school & 29 & 17.1 \\
\hline High school graduate & 47 & 27.6 \\
\hline Vocational school & 8 & 4.7 \\
\hline Some college & 25 & 14.7 \\
\hline College graduate & 42 & 24.7 \\
\hline Graduate/Professional Training & 4 & 2.4 \\
\hline Don't know & 7 & 4.1 \\
\hline \multicolumn{3}{|l|}{ Highest education level achieved by father } \\
\hline Less than 7 years of school & 5 & 2.9 \\
\hline Completed junior high & 2 & 1.2 \\
\hline Partial high school & 35 & 20.6 \\
\hline High school graduate & 45 & 26.5 \\
\hline Vocational school & 3 & 1.8 \\
\hline Some college & 18 & 10.6 \\
\hline College graduate & 28 & 16.5 \\
\hline Graduate/Professional Training & 4 & 2.4 \\
\hline Don't know & 30 & 17.6 \\
\hline
\end{tabular}


Table 2.

Descriptive Statistics for Study Variables

\begin{tabular}{|c|c|c|c|c|c|}
\hline Continuous Variables & $M$ & $S D$ & & Skewness & Kurtosis \\
\hline Sexual Abuse & 1.59 & 1.03 & & 1.83 & 2.28 \\
\hline Physical and Emotional Abuse & 2.74 & 1.01 & & .35 & -0.72 \\
\hline Physical and Emotional Neglect & 1.71 & .59 & & .81 & .28 \\
\hline Trauma Symptoms & 1.92 & .48 & & .63 & .38 \\
\hline AOD Problem Severity & 5.59 & 3.20 & & .16 & -0.56 \\
\hline Perceived Discrimination & 5.30 & 2.89 & & .40 & -0.56 \\
\hline Ethnic Orientation & 2.75 & 1.00 & & .26 & -0.39 \\
\hline Ethnic Identity & 2.62 & .82 & & .35 & -0.01 \\
\hline Dichotomous Variables & & $n$ & $\%$ & & \\
\hline Met Alcohol Abuse Diagnosis & & 69 & 40.6 & & \\
\hline Met Alcohol Dependency Diagnosis & & 34 & 20.0 & & \\
\hline Met Drug Abuse Diagnosis & & 71 & 41.8 & & \\
\hline Met Drug Dependency Diagnosis & & 46 & 27.1 & & \\
\hline
\end{tabular}


Table 3.

Intercorrelations for Study Variables

\begin{tabular}{|c|c|c|c|c|c|c|c|c|}
\hline Variable & 1 & 2 & 3 & 4 & 5 & 6 & 7 & 8 \\
\hline 1. PTSD Symptoms & --- & $.46^{* *}$ & $.30 * *$ & $.24 * *$ & $.46^{* *}$ & $-.21 * *$ & .08 & $.33 * *$ \\
\hline 2. Physical and Emotional Abuse & & --- & $.28 * *$ & $.29 * *$ & $.40 * *$ & -.04 & $.17 *$ & .14 \\
\hline 3. Sexual Abuse & & & --- & .07 & $.23 * *$ & -.06 & .04 & $.17 *$ \\
\hline 4. Physical and Emotional Neglect & & & & --- & $.18^{*}$ & $-.17 * *$ & -.01 & -.01 \\
\hline 5. Perceived Discrimination & & & & & --- & -.05 & $.29 * *$ & .08 \\
\hline 6. Ethnic Orientation & & & & & & --- & -.07 & -.04 \\
\hline 7. Ethnic Identity & & & & & & & --- & .01 \\
\hline 8. AOD Problem Severity & & & & & & & & -- \\
\hline
\end{tabular}

Notes: ${ }^{*} p<.05 .{ }^{* *} p<.01$ 
Table 4

Mean Differences for AOD Problem Severity by Grade and Family Structure

\begin{tabular}{|c|c|c|c|c|}
\hline Variable & $n$ & $M$ & $\mathrm{SE}$ & $95 \% \mathrm{CI}$ \\
\hline Ninth Grade & 39 & 5.57 & .51 & $4.74-6.77$ \\
\hline Tenth Grade & 64 & 5.64 & .42 & $4.82-6.46$ \\
\hline Eleventh Grade & 41 & 4.98 & .49 & $4.01-5.96$ \\
\hline Twelfth Grade & 26 & 5.87 & .62 & $4.66-7.11$ \\
\hline Single Parent & 79 & 5.11 & .36 & $4.39-5.82$ \\
\hline Two Parent & 91 & 6.02 & .36 & $5.30-6.74$ \\
\hline
\end{tabular}

Notes: ANOVA results indicated that there were no significant differences in AOD problem severity for either grade $(F(3,169)=.61, p=.61)$ or single parent vs. two parent family structure $(F(1,169)=3.13, p$ $=.08)$. 
Table 5

\section{Significant Model Pathway Coefficients}

\begin{tabular}{|c|c|c|c|c|c|}
\hline Path Description & $\begin{array}{c}\text { Path } \\
\text { Coefficient }\end{array}$ & $\begin{array}{l}\text { Stand. Path } \\
\text { Coefficient }\end{array}$ & $\begin{array}{l}\text { Standard } \\
\text { Error }\end{array}$ & $\begin{array}{c}95 \% \\
\mathrm{CI}\end{array}$ & $\mathrm{CR}$ \\
\hline \multicolumn{6}{|l|}{ Maltreatment \& Trauma Symptoms } \\
\hline Sex Abuse to Trauma & .04 & .08 & .03 & $.03-.10$ & 1.65 \\
\hline Phy \& Emot Abuse to Trauma & .13 & .27 & .03 & $.07-.20$ & 3.90 \\
\hline Phy \& Emot Neglect to Trauma & .07 & .08 & .05 & $.04-.17$ & 1.22 \\
\hline Sex Abuse X Discrimination to Trauma & .03 & .17 & .01 & $.01-.05$ & 2.56 \\
\hline \multicolumn{6}{|l|}{ Trauma \& AOD Use } \\
\hline Trauma to AOD Problems & 2.80 & .32 & .49 & $1.13-3.03$ & 4.28 \\
\hline Trauma to Alcohol Abuse & .76 & .20 & .33 & $.11-1.41$ & 2.29 \\
\hline Trauma to Alcohol Dependency & .96 & .25 & .40 & $.19-1.72$ & 2.46 \\
\hline Trauma to Drug Abuse & 1.57 & .42 & .38 & $.83-2.13$ & 4.14 \\
\hline Trauma to Drug Dependency & 1.73 & .42 & .41 & $.93-2.53$ & 4.25 \\
\hline Sex Abuse X EI to AOD Problems & -.41 & -.12 & .19 & $-.12--.58$ & 2.18 \\
\hline
\end{tabular}

Note: Sex Abuse $=$ Sexual Abuse, Phy \& Emot Abuse $=$ Physical and Emotional Abuse, Phy \& Emot Neglect $=$ Physical and Emotional Neglect, Trauma $=$ Trauma Symptoms, AOD Problems = AOD Problem Severity, EI = Ethnic Identity 
Table 6

Mean Differences for African-Americans and Hispanics

\begin{tabular}{|c|c|c|c|c|c|}
\hline \multirow[b]{2}{*}{ Variable } & \multicolumn{2}{|c|}{$\begin{array}{l}\text { African-Americans } \\
\quad(n=56)\end{array}$} & \multicolumn{2}{|c|}{$\begin{array}{r}\text { Hispanics } \\
(n=114)\end{array}$} & \multirow[b]{2}{*}{$t(1,168)$} \\
\hline & $M$ & $S D$ & $M$ & $S D$ & \\
\hline Sexual Abuse & 1.46 & .98 & 1.65 & 1.05 & -1.06 \\
\hline Physical and Emotional Abuse & 2.91 & 1.02 & 2.64 & 1.00 & 1.65 \\
\hline Physical and Emotional Neglect & 1.71 & .58 & 1.71 & .59 & -.01 \\
\hline Trauma Symptoms & 1.94 & .52 & 1.92 & .47 & .36 \\
\hline AOD Problem Severity & 4.55 & 3.32 & 6.10 & 3.03 & $-3.03 *$ \\
\hline Perceived Discrimination & 6.06 & 2.75 & 4.93 & 2.99 & $2.44^{*}$ \\
\hline Ethnic Orientation & 2.61 & .82 & 2.82 & 1.07 & -1.33 \\
\hline Ethnic Identity & 2.93 & .82 & 2.46 & .77 & $3.66 * *$ \\
\hline
\end{tabular}


Table 6 (continued)

\begin{tabular}{|lcccc|}
\hline & \multicolumn{2}{c}{$\begin{array}{c}\text { African-Americans } \\
(n=56)\end{array}$} & $\begin{array}{l}\text { Hispanics } \\
(n=114)\end{array}$ \\
\cline { 2 - 5 } Dichotomous Variables & $n$ & $\%$ & $n$ & $\%$ \\
\hline Met Alcohol Abuse Diagnosis & 20 & 35.7 & 49 & 43.0 \\
Met Alcohol Dependency Diagnosis & 9 & 16.1 & 25 & 21.9 \\
Met Drug Abuse Diagnosis & 18 & 32.1 & 53 & 46.5 \\
Met Drug Dependency Diagnosis & 8 & 14.2 & 38 & $33.3 *$ \\
\hline
\end{tabular}

Note: Chi-square results indicated a significant difference in the number met for drug dependency $\operatorname{diagnosis}\left(X^{2}(1)=6.90, \mathrm{p}<.01\right)$. 
Figure 1. Four Proposed Conceptual Models



Mediation Model



Mediation with Interaction Effects Model

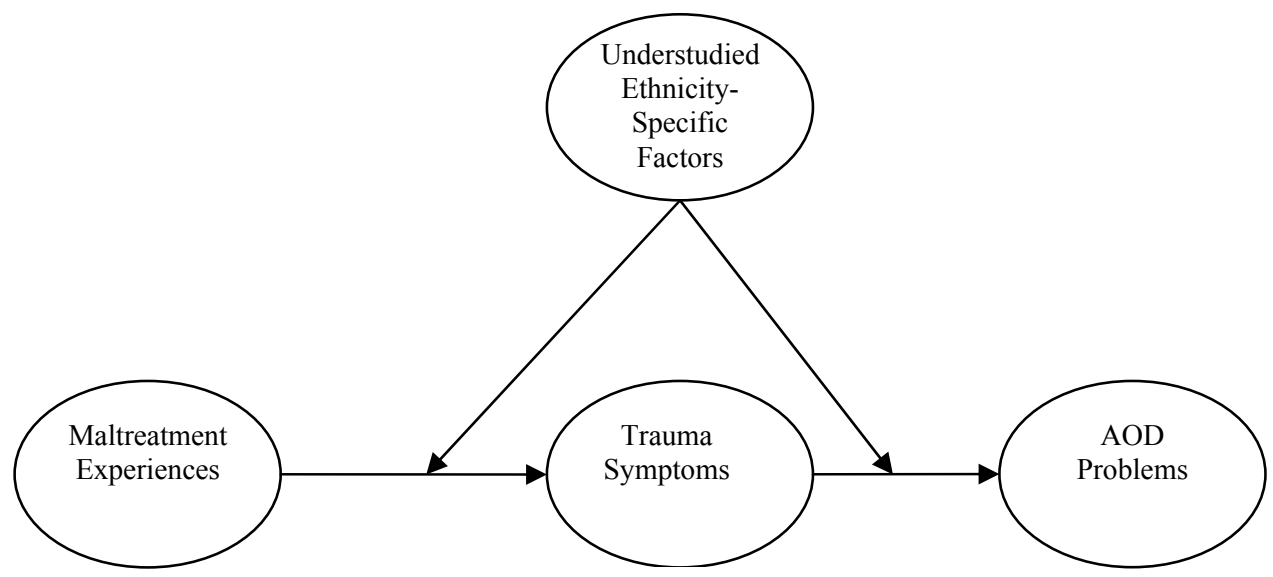

Full Model

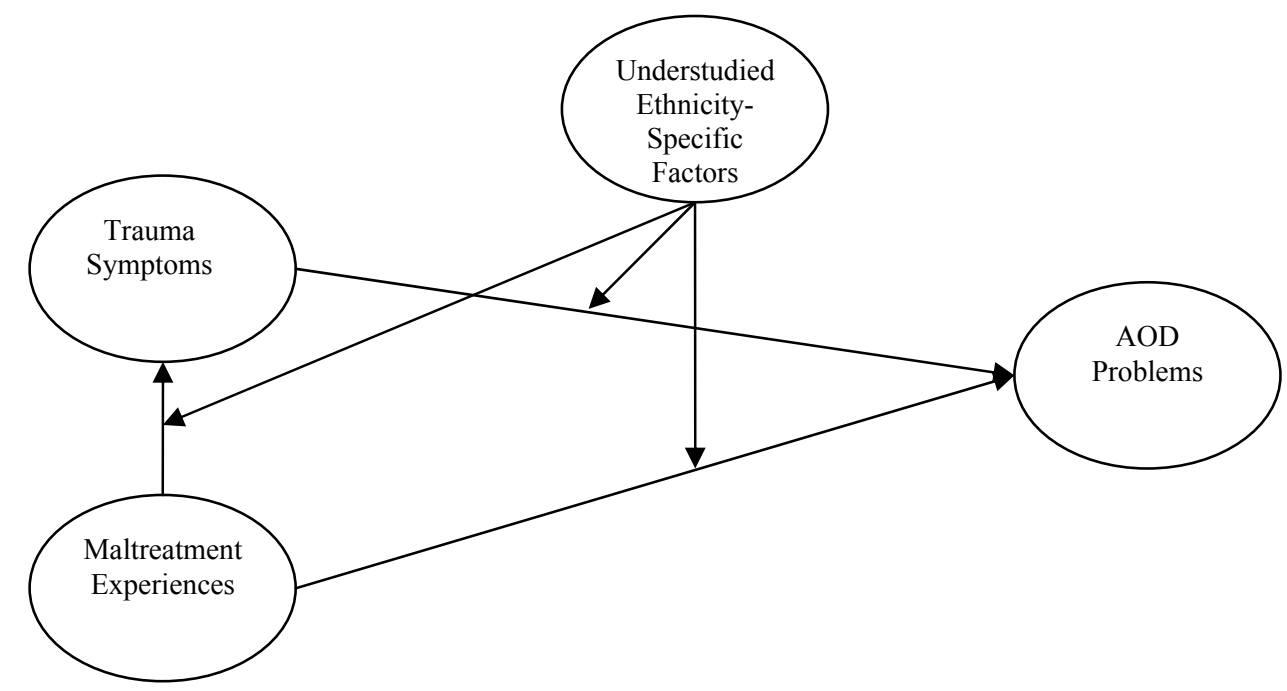


Figure 2. Full Conceptual SEM Model

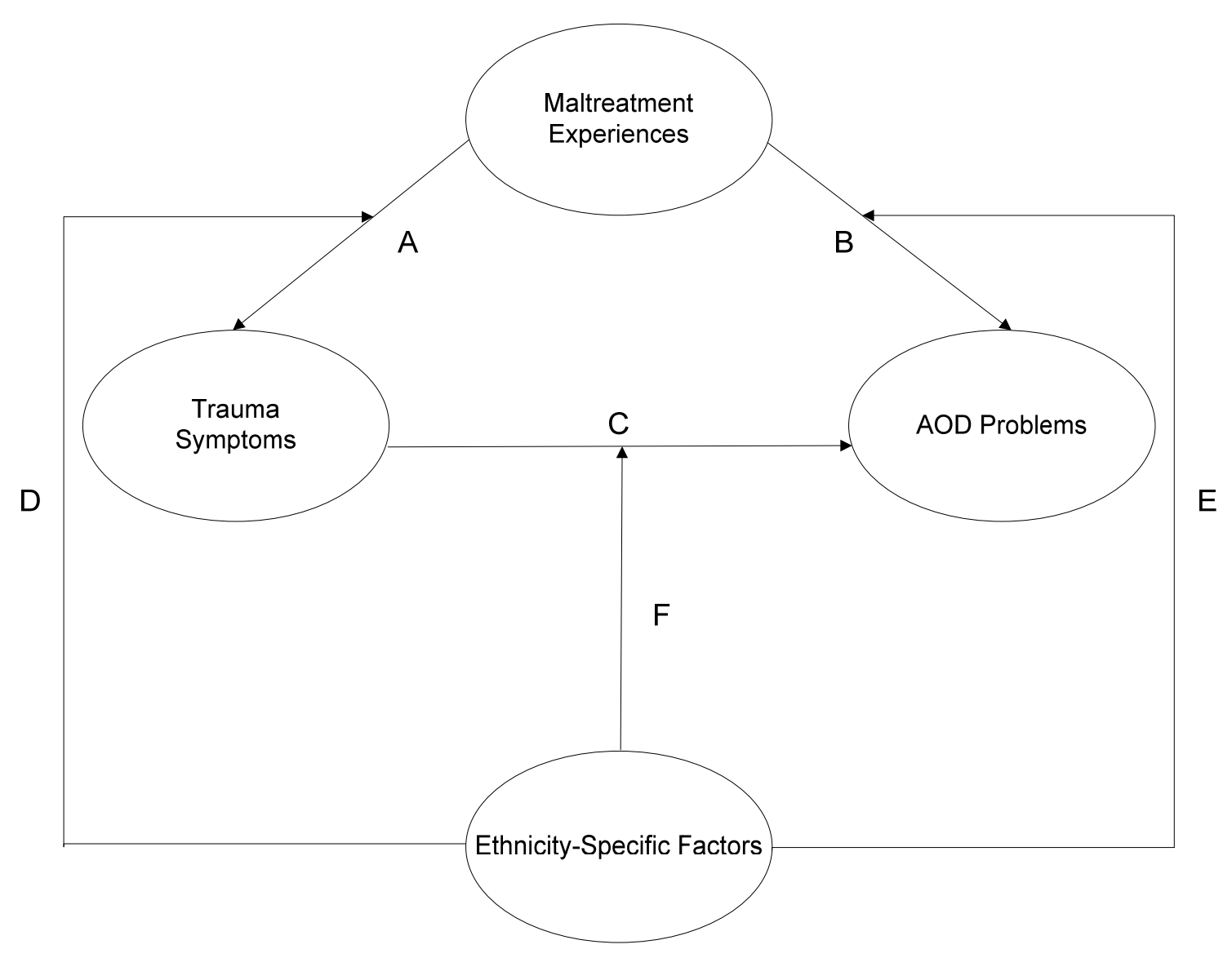


Figure 3. Final Structural Model

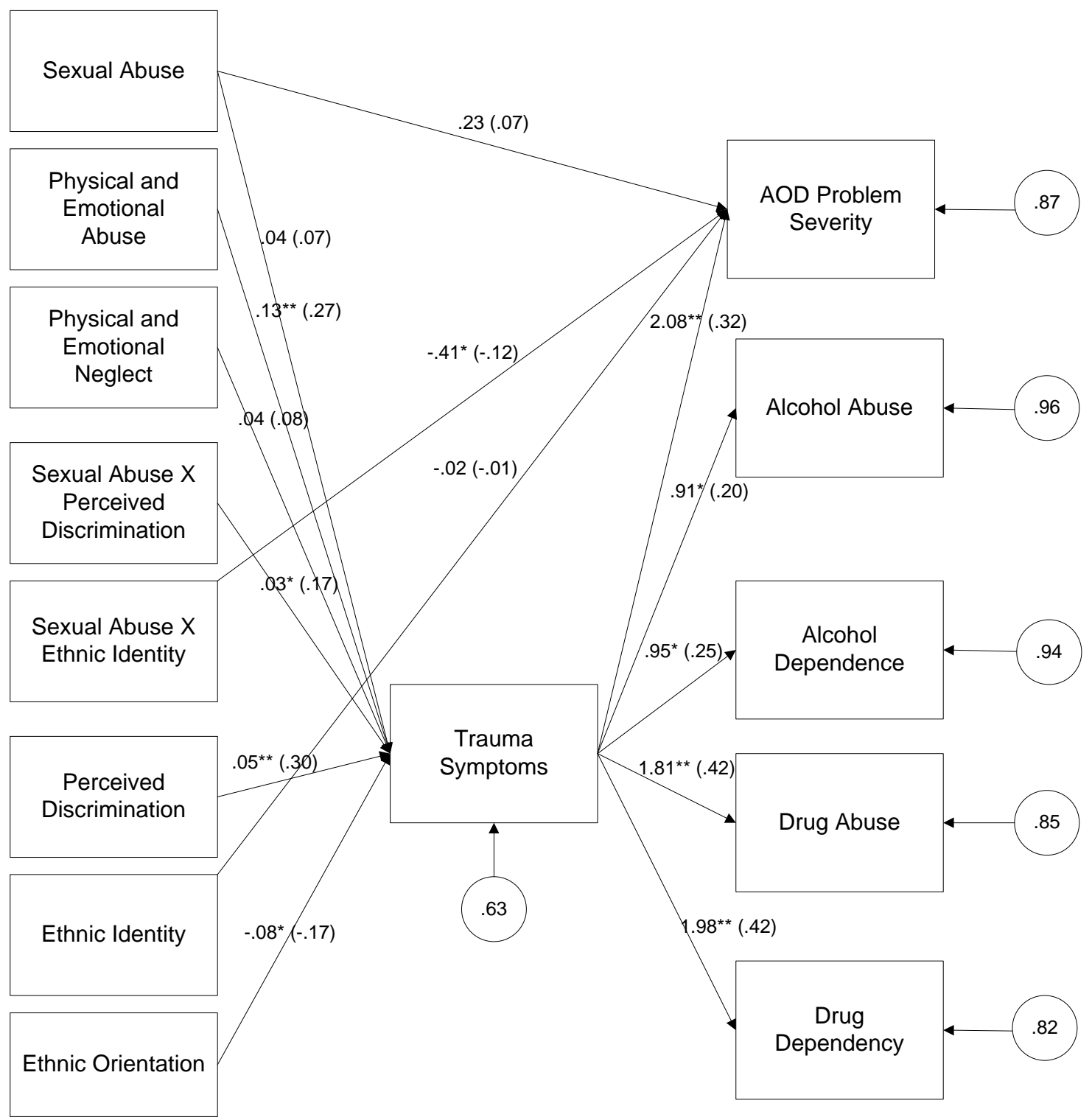

Note: Rectangles represent observed (measured) variables. The straight lines with arrows from observed variables represent presumed causal pathways. The values along the pathways are path coefficients. All standardized estimates are in parentheses. The values in the circles represent standardized error variances (percentage of unexplained variance). All exogenous variables are assumed to be correlated. All standardized error variances for dependent variables were correlated.

$* p<.05 * * p<.001$ 
Figure 4. Moderated Relation of Sexual Abuse and Trauma Symptoms by Perceived Discrimination

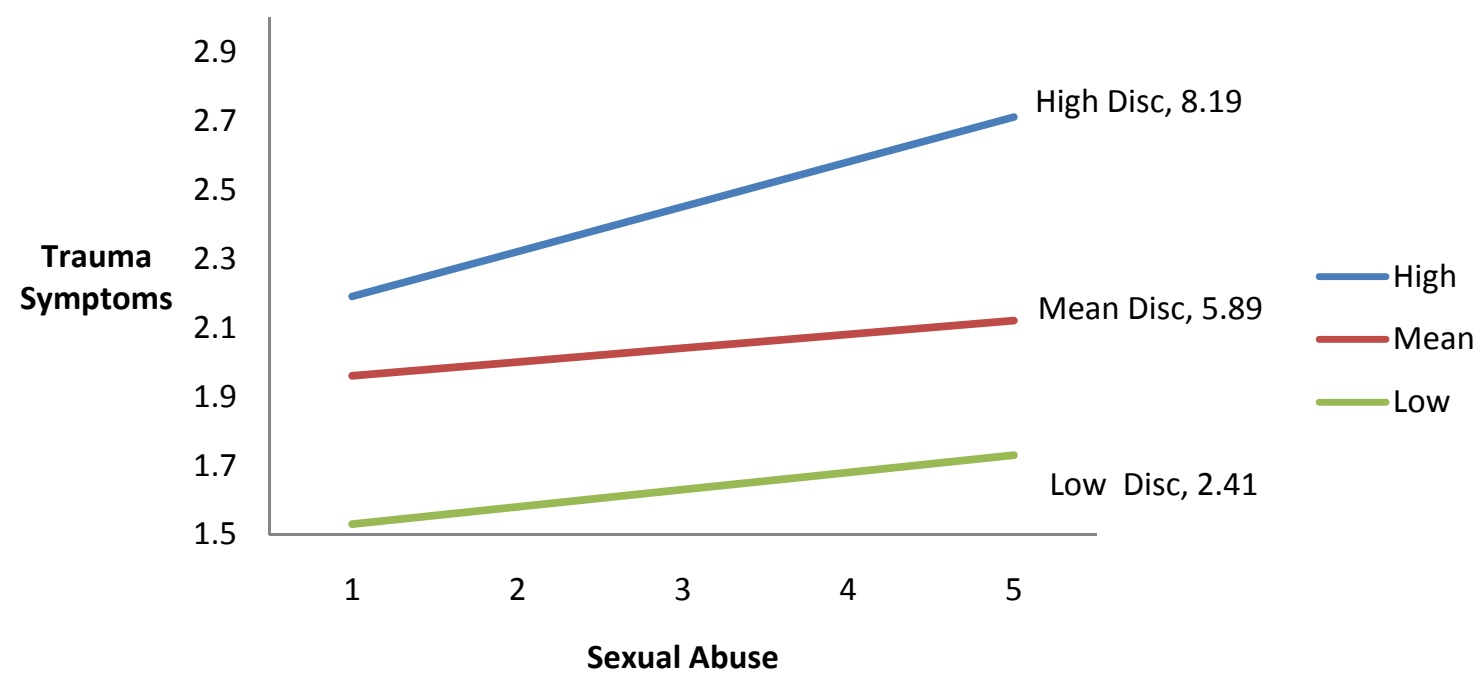

Note: Disc $=$ Perceived Discrimination; High perceived discrimination is defined as one standard above the mean and low perceived discrimination is defined as one standard deviation below the mean. 
Figure 5. Moderated Relation of Sexual Abuse and AOD Problem Severity by Ethnic Identity

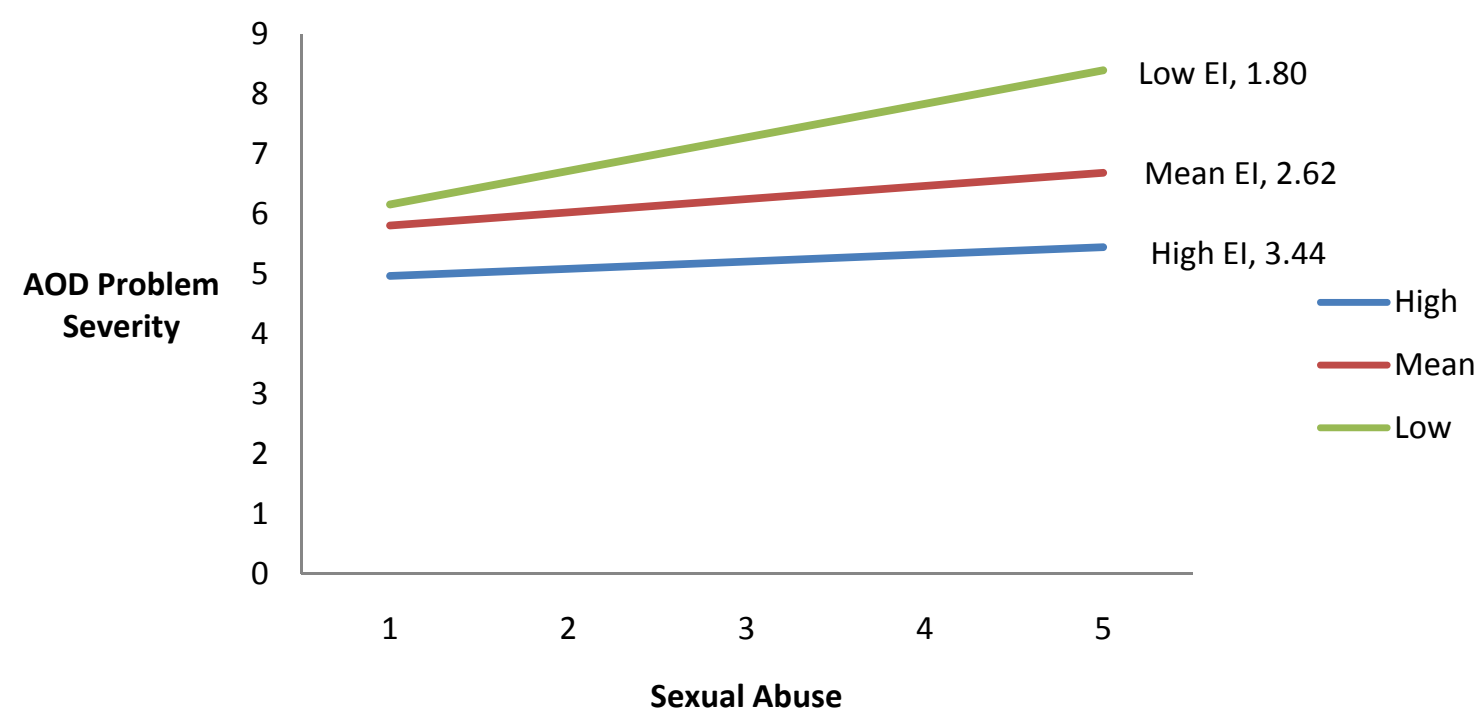

Note: $\mathrm{EI}=$ Ethnic identity; High ethnic identity is defined as one standard above the mean and low ethnic identity is defined as one standard deviation below the mean. 
VITA

\section{CALONIE MARIE KELLI GRAY}

$1997-2001$

2001-2003

2003-2006

2006-present
B.A., Psychology

University of TN at Chattanooga

Chattanooga, TN

Case Manager

Whitehaven Southwest Mental Health Center

Memphis, TN

M.S. Counseling Psychology

Florida International University

Miami, Florida

Graduate Certificate, Epidemiology/Biostatistics

Florida International University

Miami, Florida

\section{PUBLICATIONS AND PRESENTATIONS}

Gray, C.M., Montgomery, M.J., Rodriguez, A.M. \& Wagner, E.F. (2008, July). Maltreatment and alcohol and other drug use in adolescent girls. Poster presented at annual conference for the Research Society on Alcoholism, Washington D.C.

Montgomery, M.J., Gray, C.M., Rodriguez, A.M. \& Wagner, E.F. (2008, July). Familyrelated triggers for girls' AOD use: An analysis of session transcripts. Poster presented at annual conference for the Research Society on Alcoholism, Washington D.C.

Des Rosiers, S.E., Gray, C.M., Surace, F.I., \& Tubman, J.G. (2008, March). Integrating Person-Centered and Variable-Centered Frameworks: An Evaluation of Sex-Related Alcohol Expectancies Among Adolescents. Poster presented at the annual conference for the Society for Research on Adolescents, Chicago, IL.

Pienkowski, M., Gray, C.M., Hernandez, I., Sangiovanni, P., Alonso, A. Carter, R. \& Silverman, W.K. (2008, March). Overdue for a reconceptualization of the test anxiety construct in elementary schools: A new approach to identifying children at risk for anxiety disorders. Poster presented at the annual conference of Anxiety Disorders Association of America, Savannah, GA. 